Ricardo Jureidini

\title{
Análise da densidade da microvasculatura e da expressão do gene p53 no adenocarcinoma pancreático
}

Tese de apresentada à Faculdade de Medicina da Universidade de São Paulo para obtenção de título de Doutor em Ciências

Área de concentração: Cirurgia do Aparelho Digestivo

Orientador: Prof. Dr. José Eduardo Monteiro da Cunha

São Paulo 2009 

Ricardo Jureidini

\section{Análise da densidade da microvasculatura e da expressão do gene p53 no adenocarcinoma pancreático}

Tese de apresentada à Faculdade de Medicina da Universidade de São Paulo para obtenção de título de Doutor em Medicina

Área de concentração: Cirurgia do Aparelho Digestivo

Orientador: Prof. Dr. José Eduardo Monteiro da Cunha

São Paulo 2009 
Dados Internacionais de Catalogação na Publicação (CIP)

Preparada pela Biblioteca da

Faculdade de Medicina da Universidade de São Paulo

Creprodução autorizada pelo autor

Jureidini, Ricardo

Análise da densidade da microvasculatura e da expressão do gene p53 no adenocarcinoma pancreático / Ricardo Jureidini. -- São Paulo, 2009.

Tese(doutorado)--Faculdade de Medicina da Universidade de São Paulo.

Departamento de Gastroenterologia.

Área de concentração: Cirurgia do Aparelho Digestivo.

Orientador: José Eduardo Monteiro da Cunha.

Descritores: 1.Neoplasias pancreáticas 2.Neoplasias pancreáticas/genética 3.Neovascularização patológica 4.Adenocarcinoma 5.Proteína supressora de tumor p53/análise 6.Antígenos CD34/análise 7.Estadiamento de neoplasias 8.Imunoistoquímica 9.Prognóstico 10.Estudos retrospectivos

USP/FM/SBD-288/09 
"Tudo é sincrônico. A sincronia na estratégia não pode ser dominada sem uma dedicação efetiva e prática."

Myiamoto Musashi 1865. 
A minha esposa Regiany e a minha filha Laura, amores da minha vida.

Aos meus queridos pais, Claudio e Sonia. 


\section{Agradecimentos}

Este trabalho é fruto da orientação e oportunidades que venho recebendo, nesse momento manifesto a gratidão aos amigos e mestres, cujos conselhos e incentivos, durante toda a minha vida pessoal e profissional, foram indispensáveis para o meu progresso.

Ao Prof. Dr. José Eduardo Monteiro da Cunha, exemplo de professor e médico pela dedicação no desenvolvimento da minha carreira, apoio na vida pessoal e orientação segura na realização desse estudo.

A Dr. Rosely A. Patzina, pela revisão de todas as lâminas de todos os tumores pancreáticos além da precisa avaliação dos resultados da imunoistoquímica. Exemplo de dedicação e interesse.

A Sra. Neila Aparecida de Souza Silva pelo trabalho técnico da coloração imunoistoquímica no Laboratório de Anatomia Patológica do Hospital das Clínicas da Universidade de São Paulo.

Ao Doutorando Flávio Takeda, pelo entusiasmo e incansável colaboração durante todas as fases dessa pesquisa.

Ao Prof. Dr. Telesforo Bacchella, pelo incentivo constante e incansável apoio pessoal e profissional.

Ao Prof. Titular Dr.Ivan Cecconello, por permitir minha atividade profissional no Instituo do Câncer do Estado de São Paulo.

Ao Prof. Titular Dr. Luiz Augusto Carneiro D’Albuquerque, pelo apoio como Coordenador da Pós-Graduação da Disciplina de Cirurgia do Aparelho Digestivo da FMUSP.

Ao Prof. Dr. Wilson Modesto Pollara, pelo incentivo no tratamento cirúrgico dos pacientes com câncer pancreático, exemplo de médico para mim.

As Sras. Rita Ortega e Adriana Fonseca, excelentes bibliotecárias pelo auxílio na compilação dos artigos científicos, na diagramação e pelo incentivo 
constante. Imprescindíveis para a realização deste trabalho em todas as suas etapas.

À Julia Fukushima e Adriana Bruscato, pela precisa e eficiente colaboração nos estudos estatísticos dos resultados.

A Sras. Myrtes Freire de Lima e Vilma de Jesus Libério pela atenção e incentivo no meu desempenho na Pós-Graduação.

Aos colegas de Disciplina de Cirurgia do Aparelho Digestivo da Faculdade de Medicina da Universidade de São Paulo e do Instituto do Câncer do Estado de São Paulo, pela amizade, conhecimentos transmitidos e colaboração.

$\mathrm{E}$ aos pacientes que, com coragem e esperança, aceitaram o tratamento que motivou essa pesquisa. 


\section{Normalização adotada}

Essa dissertação está de acordo com as seguintes normas, em vigor no momento desta publicação:

Referências: adaptado de International Committee of Medical Journals Editors (Vancouver)

Universidade de São Paulo. Faculdade de Medicina. Serviço de Biblioteca e Documentação. Guia de apresentação de dissertações de teses e monografias. Elaborado por Annelise Carneiro da Cunha, Maria Júlia de A. L. Freddi, Maria F. Crestana, Marinalva de Souza Aragão, Suely Campos Cardoso, Valéria Vilhena, $2^{\text {a }}$. ed. São Paulo: Serviço de Biblioteca e Documentação; 2005. 


\section{Sumário}

Lista de Figuras

Lista de Tabelas

Lista de Gráficos

Resumo

Summary

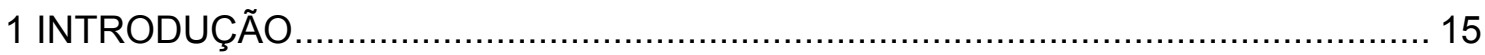

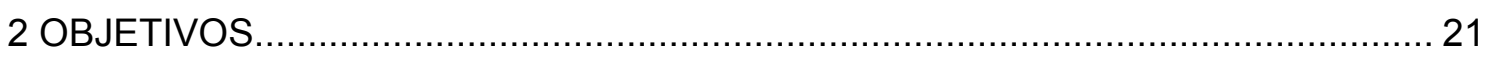

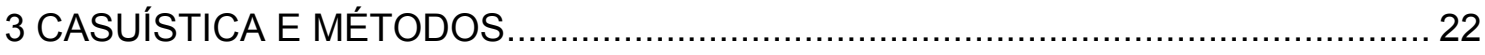

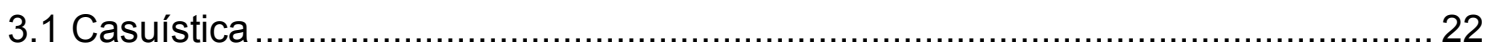

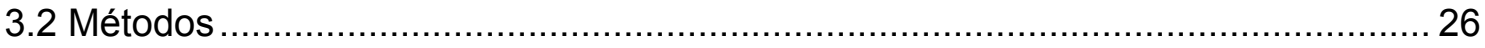

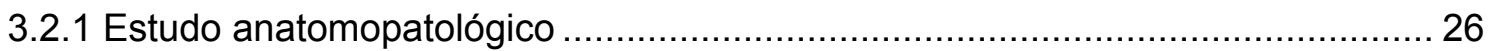

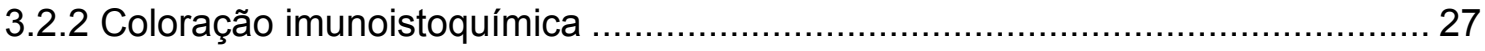

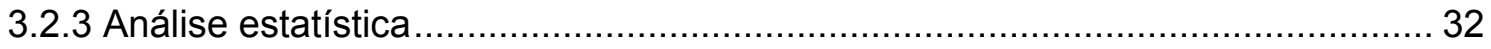

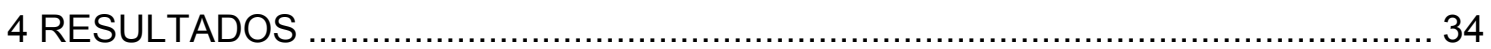

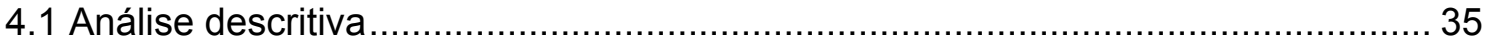

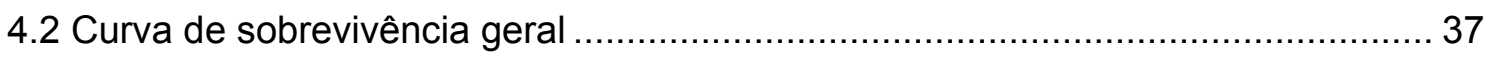

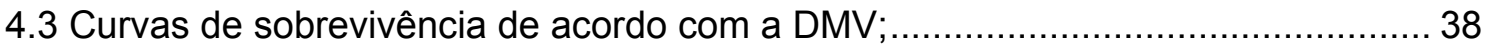

4.4 Curvas de sobrevivência de acordo com a expressão p53 ….............................. 40

4.5 Estudo da sobrevivência de acordo com a expressão p53 e DMV

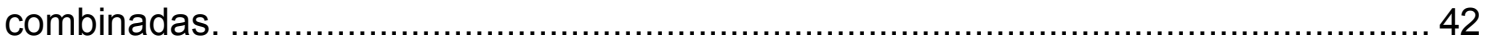

4.6 Análise da relação da DMV e diversas variáveis clínico-patológicas .................... 44

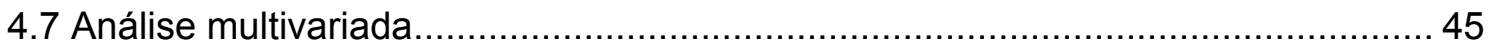

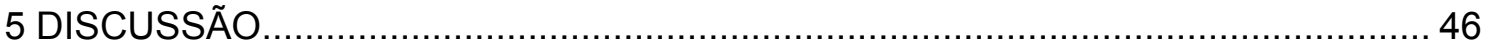

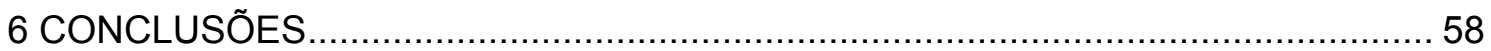

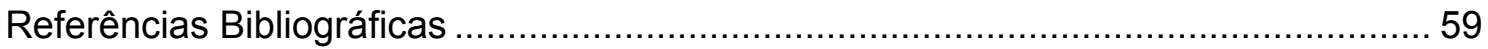

Apêndice 


\section{Lista de Figuras}

Figura 1 Linfonodos peri-pancreáticos e retro-peritoneais

Figura 2 Aspecto intra-operatório após a ressecção de tumor na cabeça pancreática.

Figura 3 Blocos parafinados e lâminas preparadas com coloração HE.

26

Figura 4 Modelo esquemático da reação imunoistoquímica.

Figura 5 llustração de alguns pontos do retículo utilizado para a contagem da DMV. Caso $n^{\circ} 3$. Coloração com anticorpo anti-CD34.

Microscopia óptica

Figura 6 Equação de conversão das unidades vaso/campo para vasos $/ \mathrm{mm}^{2}$ 


\section{Lista de Tabelas}

Tabela 1 Sistema de Estadiamento TNM da UICC/AJCC 6 ${ }^{\mathrm{a}}$ ed. 2002.

Tabela 2 Dados descritivos da casuística.

Tabela 3 Dados descritivos dos pacientes dos grupos DMV alta e baixa.

Tabela 4 Dados descritivos dos pacientes dos grupos p53 negativo e positivo

Tabela 5 Dados descritivos dos pacientes dos grupos p53

negativo/DMV baixa e p53 positivo/DMV alta.

Tabela 6 Relação da média da DMV com dados clínico-patológicos

Tabela 7 Características de estudos da DMV no câncer de pâncreas. 


\section{Lista de Gráficos}

Gráfico 1 Curva de sobrevivência geral. 37

Gráfico 2 Curvas de sobrevivência de acordo com a DMV. 39

Gráfico 3 Curvas de sobrevivência de acordo com a expressão do gene p53

Gráfico 4 Curvas de sobrevivência pela combinação p53/DMV 


\section{Resumo}

Jureidini, $R$ Análise da densidade da microvasculatura e da expressão do gene p53 no adenocarcinoma pancreático. São Paulo, 2009. Tese (doutorado) - Faculdade de Medicina, Universidade de São Paulo. 73p.

O adenocarcinoma pancreático é a neoplasia maligna mais comum do pâncreas. A alta taxa de mortalidade deve-se ao diagnóstico tardio e a alta agressividade do tumor. Freqüentemente observam-se indivíduos com neoplasias de mesmo estadio apresentarem sobrevivência diferente. Isso demonstra a necessidade de incluir mais variáveis na caracterização da doença. $O$ processo de angiogênese é essencial para o crescimento tanto do tumor primário, quanto para o metastático. A medida da densidade intratumoral da microvasculatura (DMV) por imunoistoquímica é o método mais confiável para medir a atividade angiogênica tumoral. A perda da função do gene p53 influencia a resposta à quimio e à radioterapia além de regular a angiogênese. A sobrevivência está inversamente relacionada à positividade do p53 e à DMV em neoplasias de mama, pulmão, ovários, estômago, cólon, laringe e bexiga. No adenocarcinoma pancreático os resultados são controversos. Idealizou-se essa pesquisa retrospectiva analisando-se dados clínicos e os resultados de estudos imunoistoquímicos obtidos de adenocarcinomas de pâncreas ressecados com intenção curativa. Analisou-se dados clínicos, patológicos, re-estadiamento e resultados da DMV e da expressão do gene p53 em 49 pacientes. A densidade média de microvasos foi de 46,2 vasos $/ \mathrm{mm}^{2}$ sendo que esse valor foi utilizado para dividir os pacientes em grupos de baixa ou alta densidade de vasos. A coloração para p53 nuclear foi considerada positiva em 20 de 49 pacientes (40,8\%). A DMV foi significativamente maior nos pacientes com tumores maiores que $3,0 \mathrm{~cm}$ e nos pacientes com ressecções incompletas. A expressão do gene p53 e a DMV, não foram fatores preditivos da sobrevivência pós-operatória. Não foi possível verificar relação entre a expressão do gene p53 e a densidade da microvasculatura tumoral.

Descritores: 1.Neoplasias pancreáticas 2.Neoplasias pancreáticas/genética 3.Neovascularização patológica 4.Adenocarcinoma 5.Proteína supressora de tumor p53/análise. 


\section{Summary}

Jureidini $R$ Evaluation of microvessel density and p53 in pancreatic adenocarcinoma. [thesis]. São Paulo: "Faculdade de Medicina, Universidade de São Paulo"; 2009. 73p.

The prognostic significance of microvessel density and the p53 expression was evaluated. Between 1993 and 2006, 49 patients with pancreatic adenocarcinoma were ressected with curative intention. Specimens were stained immunohistochemically with antibodies anti- p53 anti-CD34. Microvessel density (MVD) was assessed scanning ten areas of the tumoral section and counted at a high power in an adequate area. The MVD ranged from 21,2 to 54,2 vessels/mm2 (mean 46,2 vessels $/ \mathrm{mm} 2$ ). Specific nuclear staining for p53 was determined positive in 20 patients $(40,8 \%)$. The overall median survival was 24,1 months after resection and there was no difference in survival rates according to the MVD and p53 positivity. There was also no relation between the MVD and p53 expression. MVD and p53 expression could not predict survival in these patients with pancreatic adenocarcinoma. There was no correlation with p53 expression and intratumoral microvessel density. High MVD was associated with tumor size grater than $3,0 \mathrm{~cm}$ and positive margins.

Descriptors: 1 Pancreatic Neoplasms 2 Pancreatic Neoplasms /genetics 3 Neovascularization, Pathologic 4 Adenocarcinoma 5 Tumor Suppressor Protein p53/analysis. 


\section{INTRODUÇÃO}

$\mathrm{Na}$ última década, inúmeras pesquisas acumularam conhecimento suficiente para definir o câncer do aparelho digestivo como uma doença genética complexa. Estudos sobre os oncogenes, os genes supressores tumorais, a expressão anormal de fatores de crescimento e angiogênese representam os principais alvos dessas pesquisas. Entretanto, não está bem esclarecida a relação entre essas alterações genéticas, a terapêutica e a prevenção do câncer digestivo. A inibição do surgimento de metástases, a prevenção do câncer e seu tratamento são os atuais objetivos dos pesquisadores em geral.

O adenocarcinoma pancreático é a neoplasia maligna mais comum do pâncreas. Os dados do Instituto Nacional do Câncer (INCA) revelam que esta patologia corresponde a $2 \%$ de todas as neoplasias no Brasil (Brasil, 2007). Em 2007, nos Estados Unidos, estimou-se diagnosticar 37.170 casos. Nesse mesmo ano calculou-se 33.370 mortes relacionadas (Jemal et al., 2007). Essa alta taxa de mortalidade deve-se ao diagnóstico tardio e a alta agressividade do tumor. A sobrevida média global em cinco anos está abaixo de $5 \%$ e quando os pacientes são tratados cirurgicamente, esta taxa varia de 4 a 25\% (Schnelldorfer et al., 2008; Howard et al., 2006; Winter et al., 2006; 
Cress et al., 2006, Smeenk et al., 2005; Wagner ey al., 2004; Alexakis et al., 2004; Schimidt et al., 2004; Richter et al., 2003).

A duodenopancreatectomia cefálica é considerada uma das mais complexas operações do aparelho digestivo. Com o avanço técnico e multidisciplinar no cuidado dos pacientes submetidos a esse procedimento. A duodenopancreatectomia passou a ser realizada índices de mortalidade próximos de $2 \%$ com baixa morbidade (Winter et al., 2006). Nesse particular destaca-se o trabalho de Sosa et al., (1998), que demonstrou uma relação inversa entre o volume anual de operações realizadas em uma única instituição e a mortalidade cirúrgica.

A estratificação dos pacientes em estádios diversos poderia permitir uma melhor individualização da abordagem terapêutica, que pode variar entre cirurgia radical associada a tratamento radio e quimioterápico ou apenas a cuidados paliativos. Aplicando-se os sistemas de estadiamento convencionais, frequentemente observam-se indivíduos com neoplasia de mesmo estadio que apresentam sobrevivência diferente. Isso demonstra a necessidade de incluir mais variáveis na caracterização da doença. Mais ainda, a comparação entre diferentes casuísticas é complicada por falhas na caracterização histopatológica das neoplasias ressecadas (Esposito et al., 2008; Jureidini et al., 2003). Essas variáveis poderiam ser: marcadores 
tumorais séricos, expressão de genes, características de proliferação celular e vascular, entre outras.

Marcadores moleculares que apresentem influência prognóstica, também podem tornar-se eventuais alvos para tratamento específico e podem ser utilizados para o diagnóstico precoce, monitorização de pacientes de alto risco e finalmente, contribuir para o melhor entendimento da progressão do câncer pancreático.

As pesquisas nesses últimos 20 anos demonstram que eventos genéticos e epigenéticos participam da indução e da progressão do câncer pancreático. Além disso, o estudo de lesões precursoras não invasivas permitiu formular um modelo de progressão seqüencial de mutações adquiridas (Koorstra et al., 2008). Paralelamente, o surgimento de quimioterápicos que agem em sítios moleculares específicos, permitiu adaptar esquemas de tratamentos individualizados. (Albo et al., 2008).

A partir das pesquisas de Folkman, no final da década de 80 , estabeleceu-se que o processo de angiogênese é essencial para o crescimento tanto do tumor primário, quanto para o metastático. Sabe-se que o tecido tumoral necessita de um adequado suprimento sanguíneo a partir do tamanho de 1 a 2 mm. (Folkman et al., 1989; 1990; 1992). A angiogênese, também contribui para o processo de metastatização porque facilita a 
circulação de células tumorais pelos vasos neoformados e permite 0 crescimento das células em sítios distantes do tumor primário (Liotta et. al., 1991).

A contagem da densidade intra-tumoral da microvasculatura (DMV) auxiliada por imunoistoquímica é o método mais confiável para medir a atividade angiogênica tumoral. (Gasparini et al., 1995; Weidner et al., 1992). A sobrevivência está inversamente relacionada à densidade da microvasculatura em neoplasias de mama, pulmão, ovário, estômago, cólon, laringe e bexiga (Uzzan et al., 2004; Des Guetz et al., 2006; Tanigawa et al., 1996; Gasparini et al.,1993,1995,1996; Macchiarini et al., 1992).

Depois do estudo pioneiro de Ellis, em 1998, o papel da DMV como fator prognóstico no adenocarcinoma de pâncreas foi estudado com resultados conflitantes (Fujimoto et al., 1998; Ikeda et al., 1999; Stipa et al, 2002). Mais recentemente, após o surgimento das terapias anti-angionênicas, sugeriu-se que a averiguação da atividade de angiogênese tumoral poderá limitar o tratamento específico aos pacientes nos quais se antevê possível resposta (Ko et al., 2008).

O mais estudado gene supressor tumoral é o p53. Os estudos pioneiros de Hollstein et al. (1991) definiram que a perda de sua função provoca transformação maligna de células in vitro e aparecimento de 
neoplasias in vivo. A sua ação é de bloquear a divisão celular ou ativar o mecanismo de morte celular quando existe alguma alteração molecular no DNA. A proteína p53 mutada não consegue sofrer hidrólise enzimática normal e o seu acúmulo no núcleo celular indica mutação no seu gene codificador. Representa também, a incapacidade da célula tumoral sofrer sua ação reguladora. Essa função confere ao gene p53 a reputação de "guardião" do genoma celular e, por estar ligada à gênese tumoral, as mutações desse gene foram intensamente pesquisadas em inúmeros tumores humanos, inclusive no pancreático. (Nio et al., 2001, Dong et al., 2005, TalarWojnarowska et al., 2006; Koorstra et al., 2008; Garcea et al., 2005; Del Chiaro et al., 2005, Schneider et al., 2008)

Observou-se que a perda da função do gene p53 influencia na resposta à quimioterapia e à radioterapia. (Bertheau et al., 2008; Hoffmann et al., 2008; Giovanetti et al., 2006; Cascalló et al., 2005; Itaya et al., 2005; Shears et al., 1998; Ribeiro Jr. et al., 1998; Ikegushi et al., 1997; Lowe et al., 1994) e que genes supressores tumorais participam da regulação da angiogênese tumoral. (Stellmach et al., 1996; Bouck et al., 1996).

Especificamente em relação ao gene p53, observou-se que a função normal desse gene diminui a produção do mais importante fator angiogênico: o fator de crescimento de endotélio vascular (VEGF) (Mukhopadhyay et al., 1995; Ueba et al., 1994; Dameron et al., 1994; Ren, et al., 2006). No 
adenocarcinoma de pâncreas Fujioka et al., 2001 demonstrou uma forte relação entre a expressão do gene p53 e a produção de VEGF e com a densidade da microvasculatura tumoral. Após o estudo de Ren et al., em 2006, consolidou-se a importância do gene p53 na regulação da angiogênese tumoral.

Com o objetivo de contribuir para o entendimento da angiogênese no adenocarcinoma pancreático, idealizou-se essa pesquisa retrospectiva analisando-se dados clínicos e resultados de estudos imunoistoquímicos obtidos de tumores ressecados com intenção curativa. Essa análise incluiu avaliação de fatores clínicos e patológicos, re-estadiamento e avaliação da densidade de microvasculatura e da expressão do gene p53, nessa neoplasia. 


\section{OBJETIVOS}

Constituíram objetivos do presente estudo:

1. Determinar a importância prognóstica da densidade da microvasculatura e da expressão do gene $p 53$ nos pacientes tratados por adenocarcinoma de pâncreas;

2. Verificar a relação da expressão do gene p53 com a densidade da microvasculatura nos tumores pancreáticos;

3. Correlacionar a densidade de microvasculatura tumoral com características clínico-patológicas no adenocarcinoma de pâncreas. 


\section{CASUÍSTICA E MÉTODOS}

Buscou-se avaliar por método imunoistoquímico a presença da proteína p53 e a densidade da microvasculatura em amostras de tecido tumoral conservadas em blocos parafinados.

\subsection{Casuística}

Compôs essa casuística, parte de um grupo de 72 pacientes operados por adenocarcinoma de pâncreas, no período de 1993 a 2006 no Serviço de Vias Biliares e Pâncreas da Disciplina de Cirurgia do Aparelho Digestivo do Hospital das Clínicas da Faculdade de Medicina da Universidade de São Paulo.

Para a constituição dessa casuística, analisou-se retrospectivamente os prontuários clínicos dos referidos pacientes, com ênfase nos dados de tempo de segmento pós-operatório e na revisão dos laudos histopatológicos,

estabelecendo-se o seu re-estadiamento, segundo o Sistema de Estadiamento TNM da UICC/AJCC (2006). (Tabela 1) 
Tabela 1 Sistema de Estadiamento TNM da UICC/AJCC $6^{\text {a }}$ ed. 2002

\begin{tabular}{|c|c|c|c|}
\hline \multicolumn{4}{|c|}{ Tumor primário (T) } \\
\hline TX & \multicolumn{3}{|c|}{ O tumor primário não pode ser avaliado } \\
\hline T0 & \multicolumn{3}{|c|}{ Sem evidência de tumor primário } \\
\hline Tis & \multicolumn{3}{|c|}{ Carcinoma in situ } \\
\hline $\mathrm{T} 1$ & \multicolumn{3}{|c|}{ Tumor limitado ao pâncreas $\leq$ a $2 \mathrm{~cm}$ na maoir dimensão } \\
\hline $\mathrm{T} 2$ & \multicolumn{3}{|c|}{ Tumor limitado ao pâncreas $\geq 2 \mathrm{~cm}$ na maoir dimensão } \\
\hline $\mathrm{T} 3$ & \multicolumn{3}{|c|}{$\begin{array}{l}\text { O tumor se extende para além do pâncreas, mas sem envolvimento } \\
\text { do eixo celíaco ou da artéria mesentérica superior }\end{array}$} \\
\hline $\mathrm{T} 4$ & \multicolumn{3}{|c|}{ O tumor envolve o eixo celíaco ou a artéria mesentérica superior } \\
\hline \multicolumn{4}{|c|}{ Linfonodos regionais $(\mathbf{N})$} \\
\hline NX & \multicolumn{3}{|c|}{ Os linfonodos regionais não podem ser avaliados } \\
\hline No & \multicolumn{3}{|c|}{ Sem metástase nos linfonodos regionais } \\
\hline N1 & \multicolumn{3}{|c|}{ Metástase nos linfonodos regionais } \\
\hline \multicolumn{4}{|c|}{ Metástase distante (M) } \\
\hline MX & \multicolumn{3}{|c|}{ Metástases distantes não podem ser avaliadas } \\
\hline M0 & \multicolumn{3}{|c|}{ Sem metástase distante } \\
\hline M1 & \multicolumn{3}{|c|}{ Metástase distante } \\
\hline \multicolumn{4}{|c|}{ Agrupamento em estadios } \\
\hline Estádio 0 & Tis & No & M0 \\
\hline Estádio IA & $\mathrm{T} 1$ & No & M0 \\
\hline Estádio IB & $\mathrm{T} 2$ & No & M0 \\
\hline Estádio IIA & $\mathrm{T} 3$ & No & M0 \\
\hline Estádio IIB & $\mathrm{T} 1, \mathrm{~T} 2, \mathrm{~T} 3$ & N1 & M0 \\
\hline Estádio III & $\mathrm{T} 4$ & Qualquer N & M0 \\
\hline Estádio IV & Qualquer T & Qualquer N & M1 \\
\hline
\end{tabular}

Em seguida, os blocos de parafina contendo material das peças cirúrgicas foram recuperados no arquivo blocário da Divisão de Anatomia Patológica da FMUSP. Novas secções foram realizadas para exame histopatológico e identificação dos blocos que continham tecido tumoral representativo. Desses, retiraram-se cortes para a realização de estudo imunoistoquímico. 
Todos os pacientes foram submetidos a tratamento cirúrgico com intenção curativa. As operações foram realizadas de maneira padronizada (Bacchella, 1986), realizando-se a ressecção da cabeça pancreática em bloco com o ducto colédoco, vesícula biliar, duodeno e os linfonodos peripancreáticos e hilares (números $5,6,8 \mathrm{~A}, 12 \mathrm{~A}, 12 \mathrm{~B}, 13,14 \mathrm{~V}$ e 17 da nova classificação da Japan Pancreas Society - JPS (1996) (Figuras 1 e 2). Realizou-se a ressecção parcial de veia porta (VP), veia mesentérica superior (VMS) ou da confluência espleno-mesentérica (CEM) apenas quando observou-se invasão macroscópica. Quando a ressecção foi do pâncreas distal, ressecou-se em monobloco o corpo, a cauda, o baço, os vasos esplênicos e os linfonodos regionais (números 10, 11P, 11D, 14V e 18). Não foi realizada linfadenectomia ampliada em nenhum dos pacientes. (Figura 1).
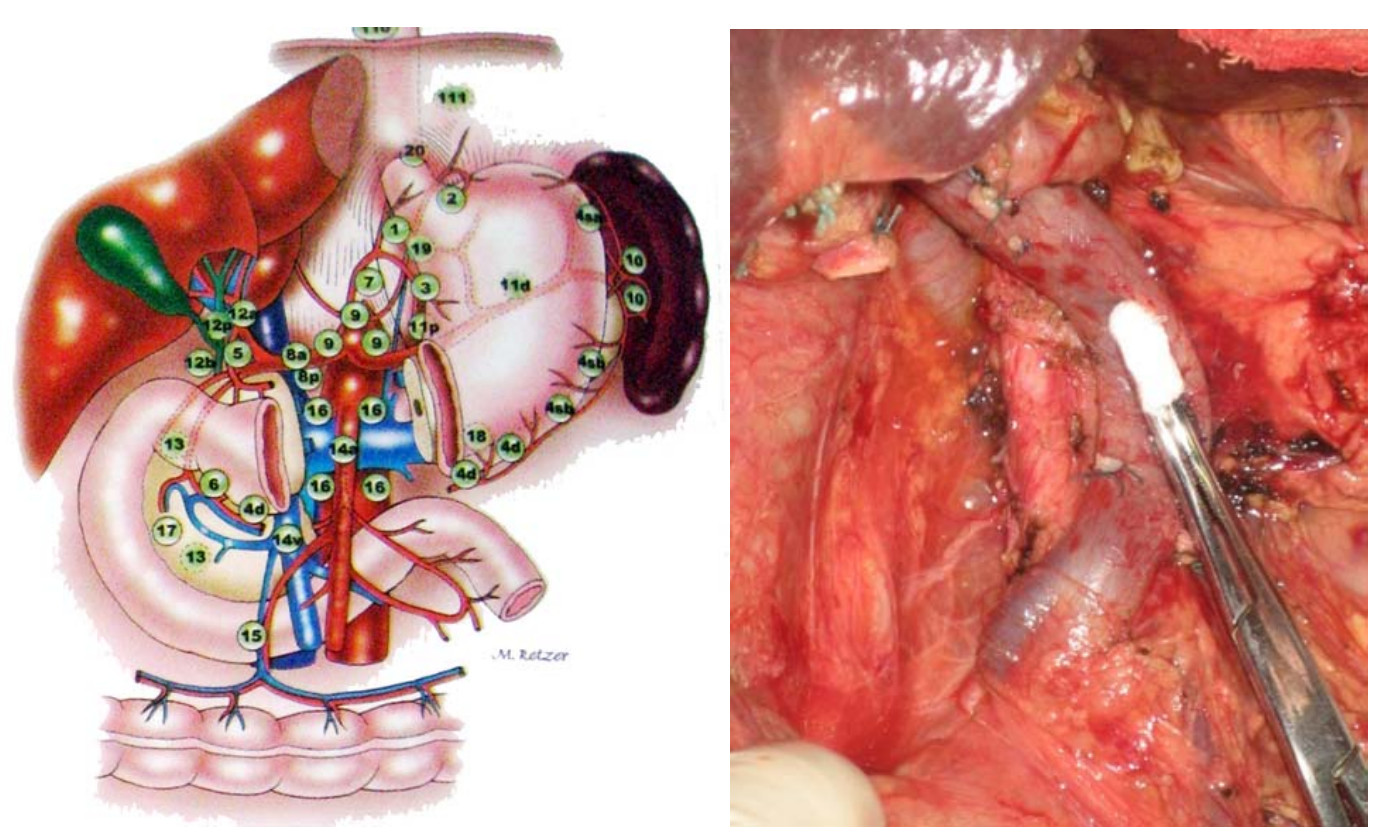

Figura 1 Linfonodos peri-pancreáticos e retro-peritoneais (esq.)

Figura 2 Aspecto intra-operatório após a ressecção de tumor na cabeça pancreática (dir.) 
Estabeleceu-se como critérios de elegibilidade o diagnóstico anátomopatológico, a ressecção tumoral, a recuperação dos blocos de parafina contendo tecido tumoral representativo da neoplasia, a presença de fatores prognósticos identificáveis (tamanho do tumor, presença de metástase linfonodal, descrição de comprometimento ou não de margens cirúrgicas, descrição de presença ou não de invasão angio-linfática e perineural) e tempo de sobrevivência pós-operatória.

Constituiu-se assim, um grupo de 49 pacientes que foram analisados com a metodologia descrita a seguir. As informações sobre o segmento pósoperatório incluíram a obtenção da data do procedimento, data do óbito ou contato em junho de 2008. Sete pacientes (14,3\%) perderam o segmento ambulatorial pós-operatório. Esses pacientes foram considerados nas curvas de sobrevivência até a data do último contato disponível.

Para análise das curvas de sobrevivência, excluíram-se dois pacientes que apresentaram óbito peri-operatório.

Quanto ao tratamento complementar, buscaram-se os dados em prontuários separados no Serviço de Oncologia da FMUSP. Obteve-se informações de 40 pacientes sendo que desses, 32 realizaram algum tratamento adjuvante ao cirúrgico. A quimioterapia mais comumente aplicada 
foi com 5-FU seguida por Gemcitabina. Dezesseis pacientes receberam radioterapia externa além de quimioterapia.

\subsection{Método}

\subsubsection{Estudo anatomopatológico}

O estudo anatomopatológico foi realizado na Divisão de Anatomia Patológica do Hospital das Clínicas da Faculdade de Medicina da Universidade de São Paulo, sob a supervisão da Dra. Rosely A. Patzina. Determinou-se o tipo histológico, o re-estadiamento TNM e a revisão do grau histológico conforme normas da Organização Mundial da Saúde. (Kloppel, 1996).

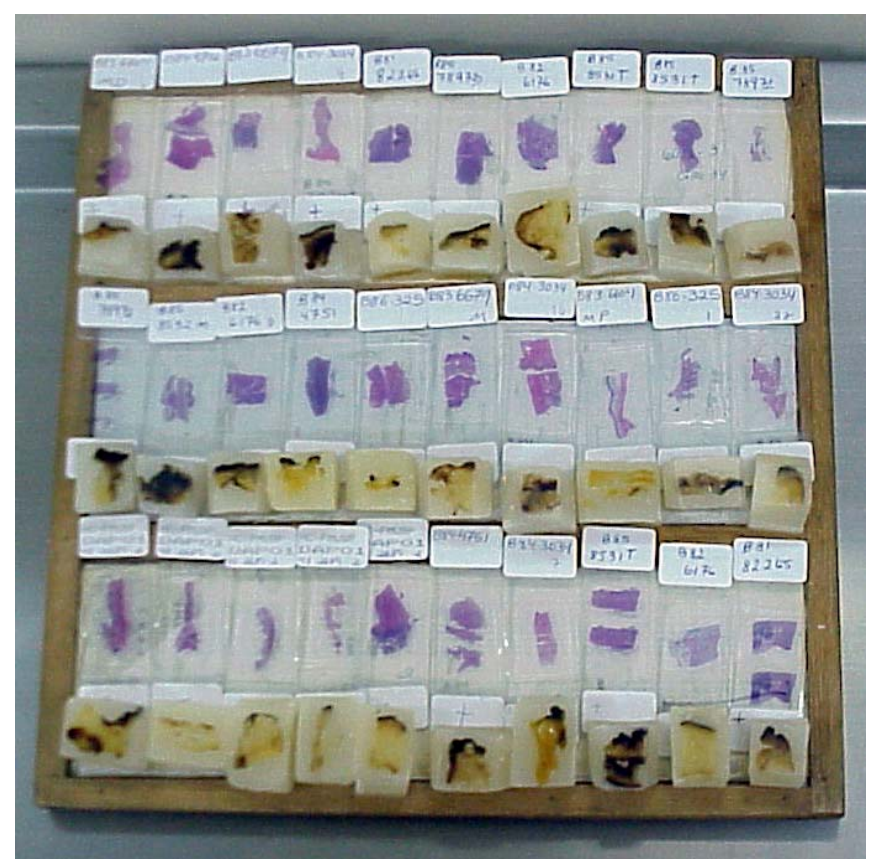

Figura 3. Blocos parafinados e lâminas preparadas com coloração HE. 


\subsubsection{Estudo imunoistoquimico}

A metodologia utilizada para realizar a reação imunoistoquimica foi descrita inicialmente por Banks et al., em 1986. Os blocos de parafina contendo tecido tumoral foram seccionados em espessura de 2-3 micrômetros e fixados em lâminas de vidro. Utilizou-se para a reação, anticorpos monoclonais anti-proteína CD34 para a coloração do endotélio dos microvasos tumorais e anti-proteína p53.

O protocolo utilizado para a reação imunoistoquímica com o anticorpo anti-CD34 foi:

1. Desparafinização das secções com xilol a $60^{\circ} \mathrm{C}$ por 30 minutos;

2. Desparafinização das secções com xilol em temperatura ambiente por mais 10 minutos;

3. Hidratação progressiva em álcool absoluto (duas vezes), em álcool 95\% (duas vezes), álcool 70\% (uma vez), água corrente (uma vez) e água destilada (uma vez);

4. Bloqueio da peroxidase endógena com água oxigenada $6 \%$ (20 volumes), por vinte minutos (uma vez), seguido de lavagem em água corrente destilada;

5. Pré-tratamento da secção a quente em panela de pressão (por dois minutos), com solução de ácido cítrico 10mM, em 6,0 de 
ph. Lavagem em água corrente, destilada e com tampão PBS (três vezes);

6. Incubação com o anti-corpo monoclonal primário anti-CD34 (clone QBEand10, código M7001, Dako®), diluído em solução de albumina a um por cento em PBS, em câmara úmida por 18 horas a $4^{\circ} \mathrm{C}$. Lavagens com tampão PBS (três vezes);

7. Incubação com o anti-corpo secundário (EP-ABCU, Novocastra ${ }^{\circledR}$ ) marcado com Biotina (LSAB+, Dako®), em câmara úmida por uma hora $37^{\circ} \mathrm{C}$. Lavagens com tampão PBS (três vezes);

8. Incubação em câmara úmida com o complexo StreptavidinaBiotina-Peroxidase $\left(\mathrm{LSAB}+\right.$, Dako®), por 30 minutos a $37^{\circ} \mathrm{C}$. Lavagens com tampão PBS (três vezes);

9. Revelação com substrato cromogênico diaminobenzidina (60 mg) diluído em uma solução de $100 \mathrm{ml}$ de PBS e 1,5ml de água oxigenada a $6 \%$, por cinco minutos. Lavagem em água corrente e destilada;

10. Contracoloração em Hematoxilina de Harrys e lavagem em água corrente e destilada;

11. Desidratação das secções em: álcool 70\% (uma vez), álcool 95\% (duas vezes), álcool absoluto (duas vezes) e xilol (três vezes);

12. Montagem em Entellan. 
Para a reação com o anti-corpo anti-p53, na etapa 5 manteve-se em panela de pressão por três minutos e meio, o anti-corpo monoclonal anti-p53 foi o Clone DO7, Código M7001, Dako® e anti-corpo secundário foi o K0690, Dako®, também marcado com Biotina (LSAB+ Dako®).

Considerou-se o resultado da avaliação imuno-histoquímica do tecido como "p53 positivo" quando dez por cento das células tumorais apresentavam coloração nuclear (Jureidini, 2003).

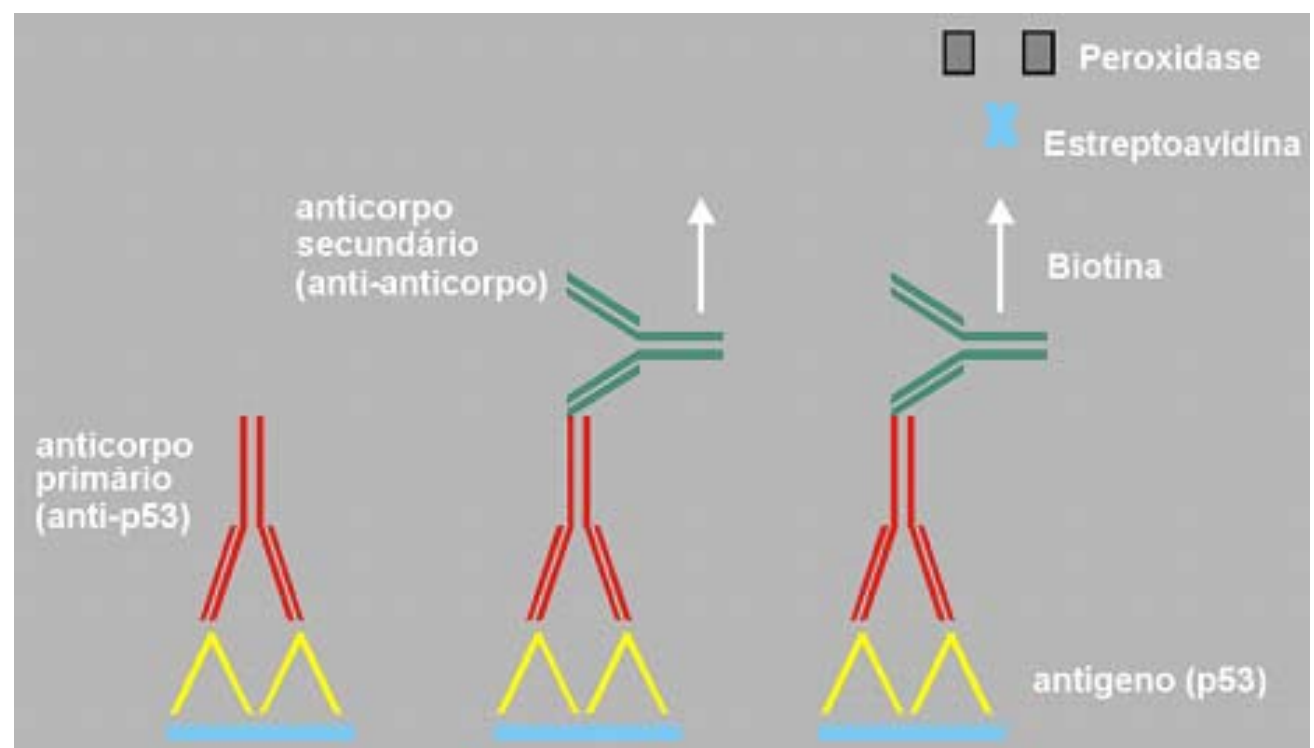

Figura 4. Modelo esquemático da reação imunoistoquímica.

Para a contagem de vasos, dez áreas da secção tumoral, foram selecionadas aleatoriamente realizando-se um movimento de "zigue-zague" em um campo visual de 40 vezes. Essa área foi então visualizada em 400 vezes de aumento utilizando-se um retículo na óptica do microscópio, com cem marcas distribuídas uniformemente em área de visualização de $754 \mu \mathrm{m}^{2}$. 
Nesse campo, a contagem de um micro-vaso foi determinada quando coincidia uma marca do retículo sobre uma célula endotelial corada. Como Weidner et al. Descreveram, em 1991, a identificação de um micro-vaso não necessitou da visualização de um lúmen vascular ou da presença de eritrócitos (Figura 5).

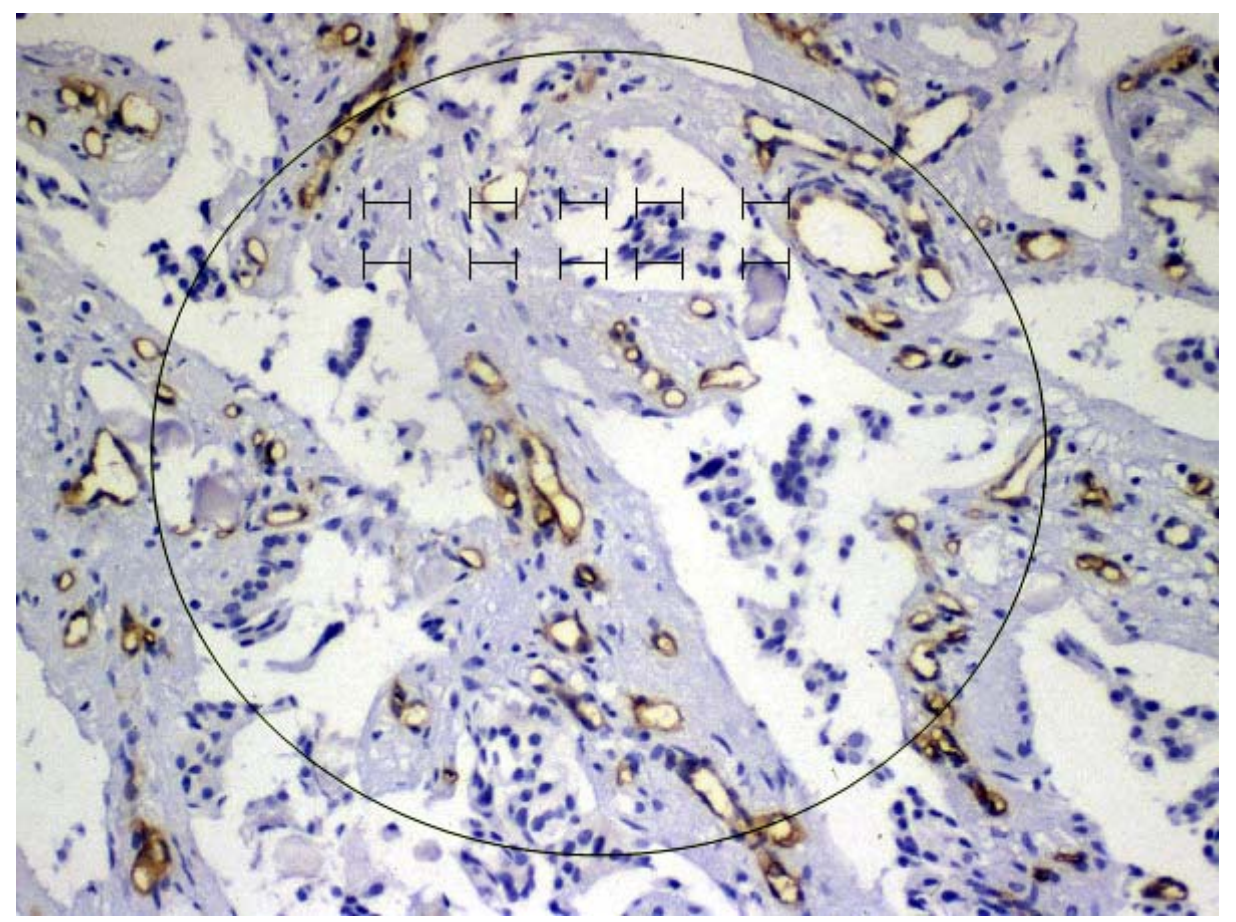

Figura 5 llustração de alguns pontos do retículo utilizado para a contagem da DMV. Caso $n^{\circ}$ 3. Coloração com anticorpo anti-CD34. Microscopia óptica (aumento de 400 vezes).

Como a área de tecido visualizada com o aumento de 400x corresponde a $754 \mu m^{2}$, utilizou-se uma equação de conversão de unidades para que a densidade de microvasos ficasse medida em vasos por milímetros quadrados - vasos $/ \mathrm{mm}^{2}$ (Figura 5). Essa conversão serviu para comparação dos resultados dessa casuística com os resultados obtidos por outros pesquisadores que utilizam essa unidade de medida para a densidade da microvasculatura tumoral. 


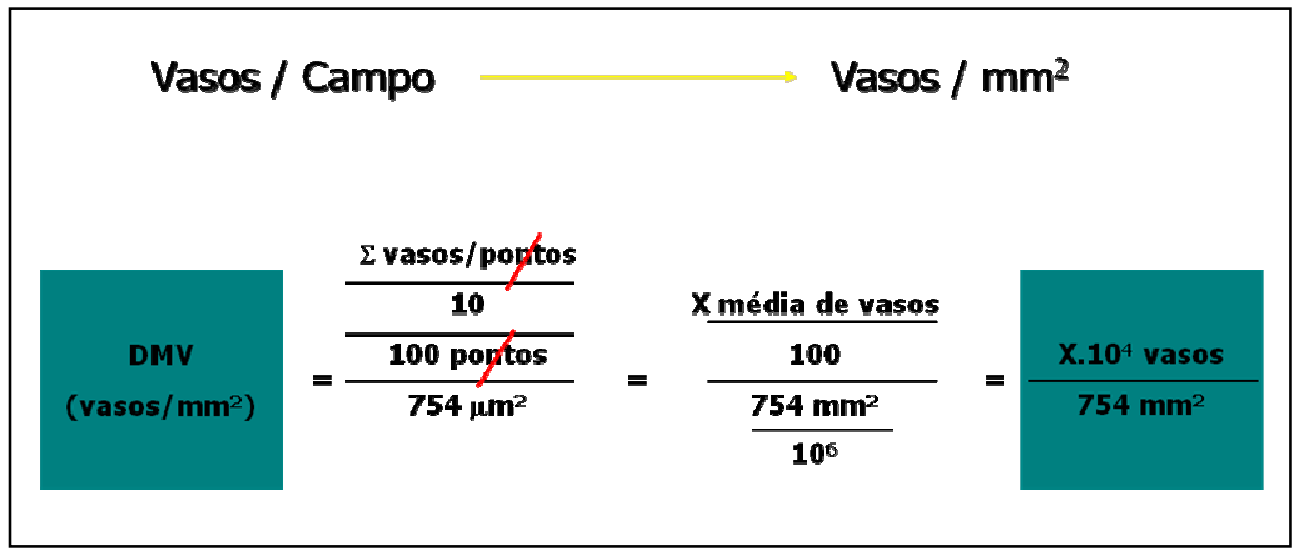

Figura 6 - Equação de conversão das unidades vaso/campo para vasos $/ \mathrm{mm}^{2}$ 


\subsubsection{Análise estatística}

Para comparar os dados pacientes, utilizaram-se os testes Quiquadrado, Exato de Fisher e T-Student para as variáveis qualitativas. As variáveis classificatórias foram descritivamente apresentadas em tabelas de contingência contendo freqüências absolutas $(n)$ e relativas (\%).

O teste Exato de Fisher foi utilizado quando, para uma determinada variável estudada, havia duas categorias (idade, sexo, N, tamanho, positividade do p53, invasão vascular e comprometimento de margem). 0 teste Qui-quadrado foi utilizado para as variáveis $T$, estadiamento e grau histológico.

O teste T-Student foi utilizado quando era possível comparar variáveis simples das quais se pode obter média e desvio padrão.

Para avaliar a influência individual de cada uma das variáveis, foram elaboradas as curvas de sobrevivência seguindo o modelo de Kaplan-Meier. O estudo das diferenças entre duas curvas de sobrevivência foi realizado aplicando-se o método de Log-Hank. 
Para análise da influência de uma variável relacionada com a DMV de forma independente, utilizou-se o modelo de linear generalizado.

Os valores de $p<0,05$ foram considerados estatisticamente significantes.

Para a realização dos cálculos e métodos estatísticos, foram empregados os programas LIFETEST e PHREG do pacote estatístico SPSS 8.0 for Windows-SAS Institute Inc. Cary, NC, USA. 


\section{RESULTADOS}

Os dados clínicos dos pacientes foram organizados em tabelas para permitir a caracterização de dados relevantes. Isso sintetizou as informações que foram posteriormente avaliadas pelos métodos estatísticos descritos acima.

As análises foram realizadas em cinco etapas:

a) análise descritiva da casuística;

b) curva de sobrevivência geral;

c) influência prognóstica das variáveis DMV e p53;

d) comparação dos pacientes dos fenótipos mais favoráveis e menos favoráveis em relação à DMV e expressão do gene p53.

e) correlação da expressão de DMV com fatores clinico-patológicos;

f) análise multivariada dos resultados.

Nas etapas onde se utilizou curvas de sobrevivência (c e d); os dados dos dois grupos que constituem a curva foram comparados em tabelas com as suas características clínico-patológicas. Isso permitiu evidenciar a homogeneidade dos grupos e o estudo das diferenças entre as curvas de sobrevivência. 
$\mathrm{Na}$ análise da relação entre a DMV e os diversos fatores clinicopatológica, considerou-se: a idade, o sexo, estádio T e N, tamanho do tumor, o grau histológico, o comprometimento das margens cirúrgicas e a expressão do $\mathrm{p} 53$

\subsection{Análise descritiva}

Nos 49 pacientes que compuseram a casuística, a idade média foi de 58,3 anos, sendo 27 mulheres. Em 46 pacientes o tumor localizava-se na cabeça do pâncreas $(93,8$ \%).

Trinta e um pacientes apresentavam-se em estadio igual ou superior ao IIB (63,2\%). Em 32 pacientes, o tumor era pT3 (65,3\%), 29 apresentavam linfonodos comprometidos (59,2\%), 45 possuíam invasão perineural $(91 ; 8 \%)$ e 26 invasão vascular $(53,1 \%)$. O diâmetro médio dos tumores foi de 3,32cm (variou entre 1,5 e 6,5cm). Observaram-se margens cirúrgicas comprometidas em 18 tumores ressecados $(36,7 \%)$ e sete pacientes apresentavam tumores indiferenciados (14,3\%). Dez pacientes foram submetidos a ressecção parcial de VP, VMS ou da CEM $(20,4 \%)$.

A densidade média de microvasos variou de 1,6 a 7,1 vasos/campo ou seja de 21,2 a 94,1 vasos $/ \mathrm{mm}^{2}$. A média dessa distribuição foi de 46,2 vasos $/ \mathrm{mm}^{2}$ sendo que esse valor foi utilizado para distribuir os pacientes em 
grupos de baixa ou alta densidade de vasos. A coloração para p53 nuclear foi considerada positiva em 20 pacientes (40,8\%) (Tabela 2).

Tabela 2. Dados descritivos de casuística

\begin{tabular}{|c|c|c|c|}
\hline Variável & & $\mathbf{N}$ & $\%$ \\
\hline \multicolumn{4}{|l|}{ Sexo } \\
\hline & feminino & 27 & $55,1 \%$ \\
\hline & masculino & 22 & $44,9 \%$ \\
\hline \multicolumn{4}{|l|}{ Idade } \\
\hline & média $=58,3$ (40-77anos) & & \\
\hline \multicolumn{4}{|c|}{ 年 } \\
\hline & 1 & 5 & $10,2 \%$ \\
\hline & 2 & 8 & $16,3 \%$ \\
\hline & 3 & 32 & $65,3 \%$ \\
\hline & 4 & 4 & $8,2 \%$ \\
\hline \multicolumn{4}{|c|}{ (2) } \\
\hline & negativo & 20 & $40,8 \%$ \\
\hline & positivo & 29 & $59,2 \%$ \\
\hline \multicolumn{4}{|l|}{ Estadio } \\
\hline & IA & 4 & $8,2 \%$ \\
\hline & IB & 5 & $10,2 \%$ \\
\hline & IIA & 9 & $18,4 \%$ \\
\hline & IIB & 27 & $55,1 \%$ \\
\hline & III & 4 & $8,2 \%$ \\
\hline \multicolumn{4}{|c|}{ Invasão Perineural } \\
\hline & ausente & 4 & $8,2 \%$ \\
\hline & presente & 45 & $91,8 \%$ \\
\hline \multicolumn{4}{|c|}{ Invasão Vascular } \\
\hline & ausente & 23 & $46,9 \%$ \\
\hline & presente & 26 & $53,1 \%$ \\
\hline \multicolumn{4}{|l|}{ Tamanho } \\
\hline & média $=3,32(1,5-6,5 \mathrm{~cm})$ & & \\
\hline & $<3,0 \mathrm{~cm}$ & 20 & $40,8 \%$ \\
\hline & $\geq 3,0 \mathrm{~cm}$ & 29 & $59,2 \%$ \\
\hline \multicolumn{4}{|c|}{ Grau Histológico } \\
\hline & bem diferenciado & 23 & $46,9 \%$ \\
\hline & moderadamente diferenciado & 19 & $38,8 \%$ \\
\hline & indiferenciado & 7 & $14,3 \%$ \\
\hline \multicolumn{4}{|l|}{ Margem* } \\
\hline & livre & 30 & $61,2 \%$ \\
\hline & comprometida & 18 & $36,7 \%$ \\
\hline \multicolumn{4}{|c|}{ Ressecção vascular } \\
\hline & não & 39 & $79,6 \%$ \\
\hline & $\operatorname{sim}$ & 10 & $20,4 \%$ \\
\hline \multicolumn{4}{|l|}{ DMV } \\
\hline & média $=46,2(21,2-94,1)$ & & \\
\hline & $<46,2$ & 28 & $57,1 \%$ \\
\hline & $\geq 46,2$ & 21 & $42,9 \%$ \\
\hline \multicolumn{4}{|l|}{ p53 } \\
\hline & negativo & 29 & $59,2 \%$ \\
\hline & positivo & 20 & $40,8 \%$ \\
\hline
\end{tabular}

\footnotetext{
* Um paciente sem informação.
} 


\subsection{Curva de sobrevivência geral}

A curva de sobrevivência geral elaborada pelo modelo de KaplanMeier demonstrou que a sobrevivência média foi de 24,1 meses. Quatro pacientes $(8,5 \%)$ permaneceram vivos sendo que três sem evidência de doença. O seguimento pós-operatório variou de 3,0 a 89,2 meses. Trinta e seis pacientes faleceram por causas relacionadas a neoplasia $(73,5 \%)$

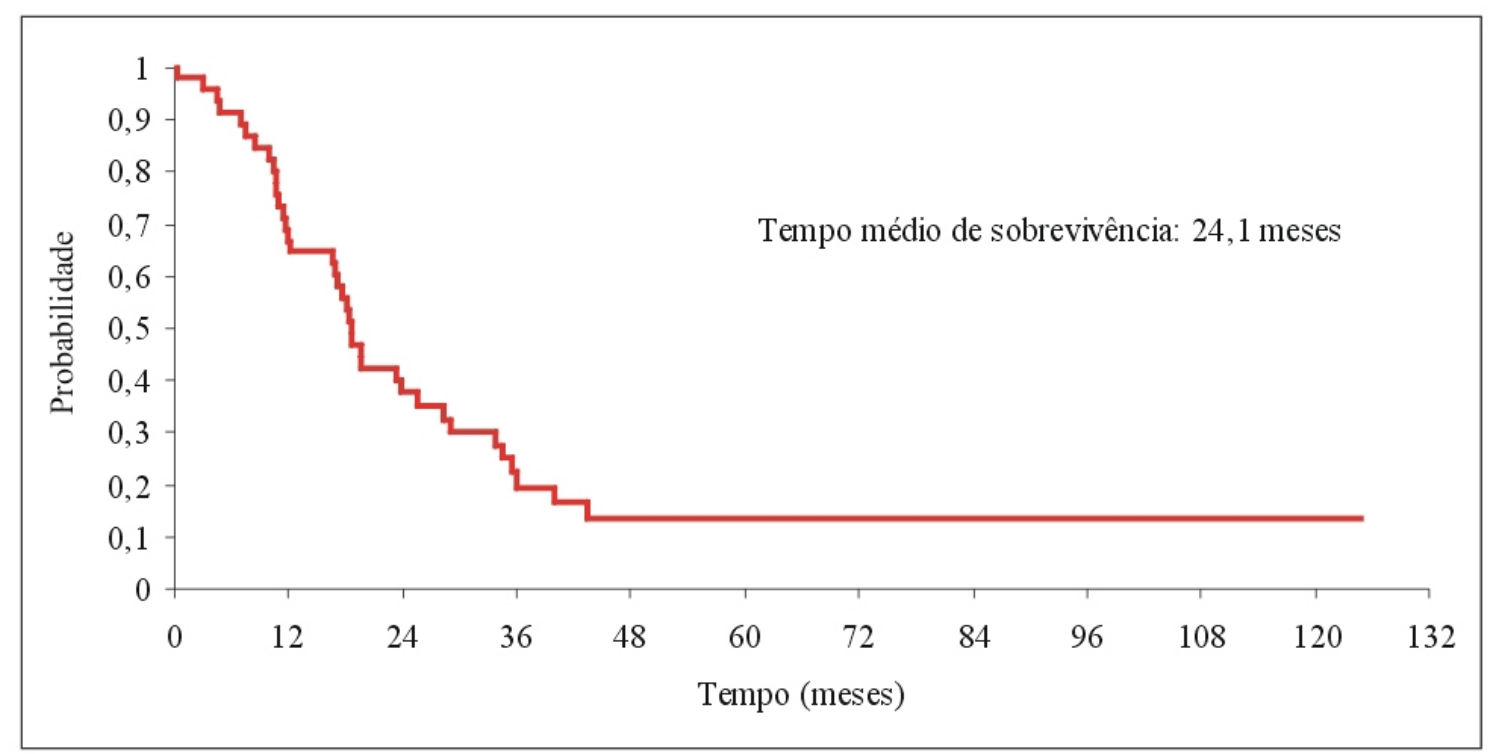

Gráfico 1. Curva de sobrevivência geral. 


\subsection{Curvas de sobrevivência de acordo com a DMV}

A tabela 3 mostra que os grupos com baixa e alta DMV são semelhantes quanto as suas características clinico-patológicas e as curvas de sobrevivência elaboradas pelo método de Kaplan-Meier e comparadas pelo método de Log-Rank, ilustradas no gráfico 3, demonstram que não houve nenhuma diferença na sobrevivência com essa estratificação.

Tabela 3 Dados descritivos dos pacientes dos grupos DMV alta e baixa

\begin{tabular}{|c|c|c|c|c|}
\hline Variável & & DMV baixa & DMV alta & $p$ \\
\hline \multicolumn{5}{|l|}{ Idade } \\
\hline & $<52$ anos & 8 & 6 & 0,99 \\
\hline & $\geq 52$ anos & 20 & 15 & \\
\hline \multicolumn{5}{|l|}{ Sexo } \\
\hline & masculino & 15 & 12 & 0,99 \\
\hline & feminino & 13 & 9 & \\
\hline \multicolumn{5}{|l|}{$\mathrm{T}$} \\
\hline & 1 & 2 & 3 & 0,72 \\
\hline & 2 & 5 & 3 & \\
\hline & 3 & 18 & 14 & \\
\hline & 4 & 3 & 1 & \\
\hline \multicolumn{5}{|l|}{$\mathrm{N}$} \\
\hline & negativo & 12 & 8 & 0,77 \\
\hline & positivo & 16 & 13 & \\
\hline \multicolumn{5}{|l|}{ Tamanho } \\
\hline & $<3,0 \mathrm{~cm}$ & 13 & 7 & 0,76 \\
\hline & $\geq 3,0 \mathrm{~cm}$ & 15 & 14 & \\
\hline \multicolumn{5}{|c|}{ Grau Histológico } \\
\hline & bem diferenciado & 14 & 9 & 0,23 \\
\hline & moderadamente diferenciado & 12 & 7 & \\
\hline & indiferenciado & 2 & 5 & \\
\hline \multicolumn{5}{|c|}{ Invasão Vascular } \\
\hline & ausente & 13 & 10 & 0,99 \\
\hline & presente & 15 & 11 & \\
\hline \multicolumn{5}{|l|}{ margem } \\
\hline & $\begin{array}{l}\text { livre } \\
\text { comprometida }\end{array}$ & $\begin{array}{l}20 \\
7\end{array}$ & $\begin{array}{l}10 \\
11\end{array}$ & 0,13 \\
\hline
\end{tabular}




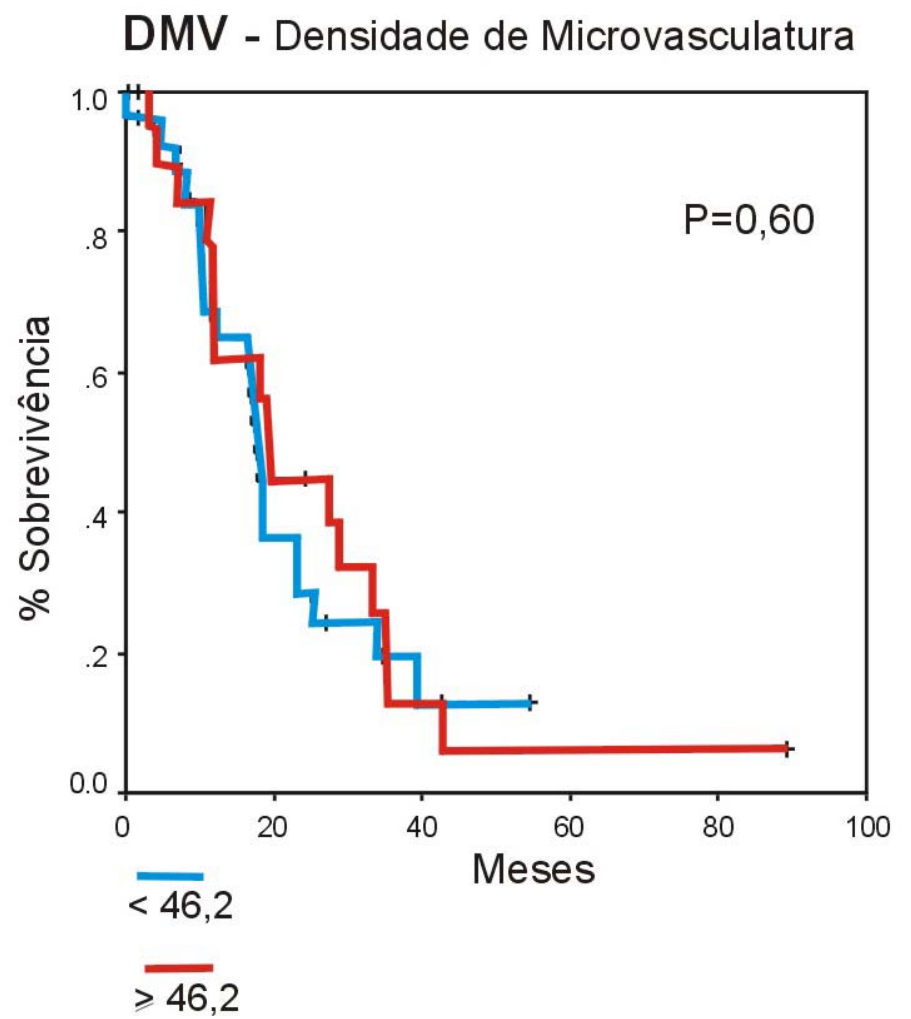

Gráfico 2. Curvas de sobrevivência de acordo com a DMV. 


\subsection{Curvas de sobrevivência de acordo com a expressão p53}

A tabela 4 mostra que os grupos p53 negativos e positivos são semelhantes quanto as suas características clinico-patológicas e as curvas de sobrevivência elaboradas pelo método de Kaplan-Meier e comparadas pelo método de Log-Rank, ilustradas no gráfico 3, demonstram que não houve nenhuma diferença na sobrevivência com essa estratificação.

Tabela 4 Dados descritivos dos pacientes dos grupos p53 negativo e positivo

\begin{tabular}{|c|c|c|c|c|}
\hline Variável & & p53 negativo & p53 positivo & $p$ \\
\hline \multicolumn{5}{|l|}{ Idade } \\
\hline & $<52$ anos & 7 & 7 & \multirow[t]{2}{*}{0,52} \\
\hline & $\geq 52$ anos & 22 & 13 & \\
\hline \multicolumn{5}{|l|}{ Sexo } \\
\hline & feminino & 12 & 15 & \multirow[t]{2}{*}{0,04} \\
\hline & masculino & 17 & 5 & \\
\hline \multicolumn{5}{|l|}{$\mathbf{T}$} \\
\hline & 1 & 2 & 3 & \multirow[t]{4}{*}{0,21} \\
\hline & 2 & 7 & 1 & \\
\hline & 3 & 16 & 16 & \\
\hline & 4 & 4 & 0 & \\
\hline \multicolumn{5}{|l|}{$\mathbf{N}$} \\
\hline & negativo & 11 & 9 & \multirow[t]{2}{*}{0,77} \\
\hline & positivo & 18 & 11 & \\
\hline \multicolumn{5}{|c|}{ Tamanho } \\
\hline & $<3,0 \mathrm{~cm}$ & 11 & 9 & \multirow[t]{2}{*}{0,77} \\
\hline & $\geq 3,0 \mathrm{~cm}$ & 18 & 11 & \\
\hline \multicolumn{5}{|c|}{ Grau Histológico } \\
\hline & bem diferenciado & 12 & 11 & \multirow[t]{3}{*}{0,41} \\
\hline & moderadamente diferenciado & 12 & 7 & \\
\hline & indiferenciado & 5 & 2 & \\
\hline \multicolumn{5}{|c|}{ Invasão Vascular } \\
\hline & ausente & 14 & 9 & \multirow[t]{2}{*}{1,0} \\
\hline & presente & 15 & 11 & \\
\hline \multicolumn{5}{|l|}{ Margem } \\
\hline & livre & 19 & 11 & \multirow[t]{2}{*}{0,55} \\
\hline & comprometida & 9 & 9 & \\
\hline
\end{tabular}




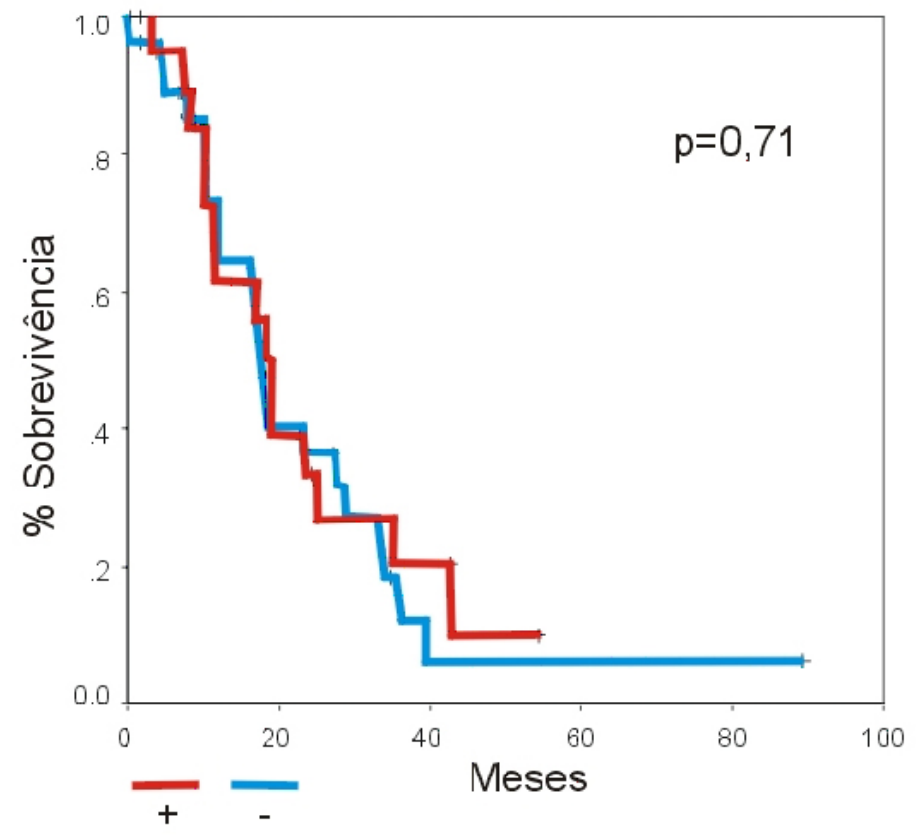

Gráfico 3. Curvas de sobrevivência de acordo com o p53. 


\subsection{Estudo da sobrevivência de acordo com a expressão p53 e DMV combinadas}

A tabela 5 mostra que os grupos p53 negativo/DMV baixa e p53 positivo/DMV alta são semelhantes quanto as suas características clinicopatológicas e as curvas de sobrevivência elaboradas pelo método de KaplanMeier e comparadas pelo método de Log-Rank, ilustradas no gráfico 5, demonstram que não houve nenhuma diferença na sobrevivência com essa estratificação.

Tabela 5 Dados descritivos dos pacientes dos grupos p53 negativo/DMV baixa e p53 positivo/DMV alta

\begin{tabular}{|c|c|c|c|c|}
\hline Variável & & $\begin{array}{l}\text { p53neg+DMV } \\
\text { baixa }\end{array}$ & $\begin{array}{l}\text { p53pos+DMV } \\
\text { alta }\end{array}$ & $\mathbf{p}$ \\
\hline \multicolumn{5}{|l|}{ Idade } \\
\hline & $<52$ anos & 5 & 4 & \multirow[t]{2}{*}{0,39} \\
\hline & $\geq 52$ anos & 13 & 10 & \\
\hline \multicolumn{5}{|l|}{ Sexo } \\
\hline & feminino & 7 & 7 & \multirow[t]{2}{*}{0,23} \\
\hline & masculino & 11 & 3 & \\
\hline \multicolumn{5}{|c|}{ (1) } \\
\hline & 1 & 1 & 2 & \multirow[t]{4}{*}{0,55} \\
\hline & 2 & 5 & 1 & \\
\hline & 3 & 9 & 7 & \\
\hline \multirow{2}{*}{\multicolumn{5}{|c|}{$\mathrm{N}$}} \\
\hline & & & & \\
\hline & negativo & 8 & 5 & \multirow[t]{2}{*}{0,99} \\
\hline & positivo & 10 & 5 & \\
\hline \multicolumn{5}{|l|}{ Tamanho } \\
\hline & $<3,0 \mathrm{~cm}$ & 6 & 3 & \multirow{2}{*}{1,00} \\
\hline & $\geq 3,0 \mathrm{~cm}$ & 12 & 7 & \\
\hline \multicolumn{5}{|c|}{ Grau Histológico } \\
\hline & $\begin{array}{l}\text { bem diferenciado } \\
\text { moderadamente }\end{array}$ & 9 & 6 & \multirow[t]{3}{*}{0,19} \\
\hline & diferenciado & 7 & 2 & \\
\hline & indiferenciado & 2 & 2 & \\
\hline \multicolumn{5}{|c|}{ Invasão Vascular } \\
\hline & ausente & 9 & 5 & \multirow{2}{*}{1,00} \\
\hline & presente & 9 & 5 & \\
\hline 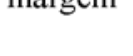 & livre & 12 & 3 & 0,11 \\
\hline & comprometida & 6 & 7 & \\
\hline
\end{tabular}




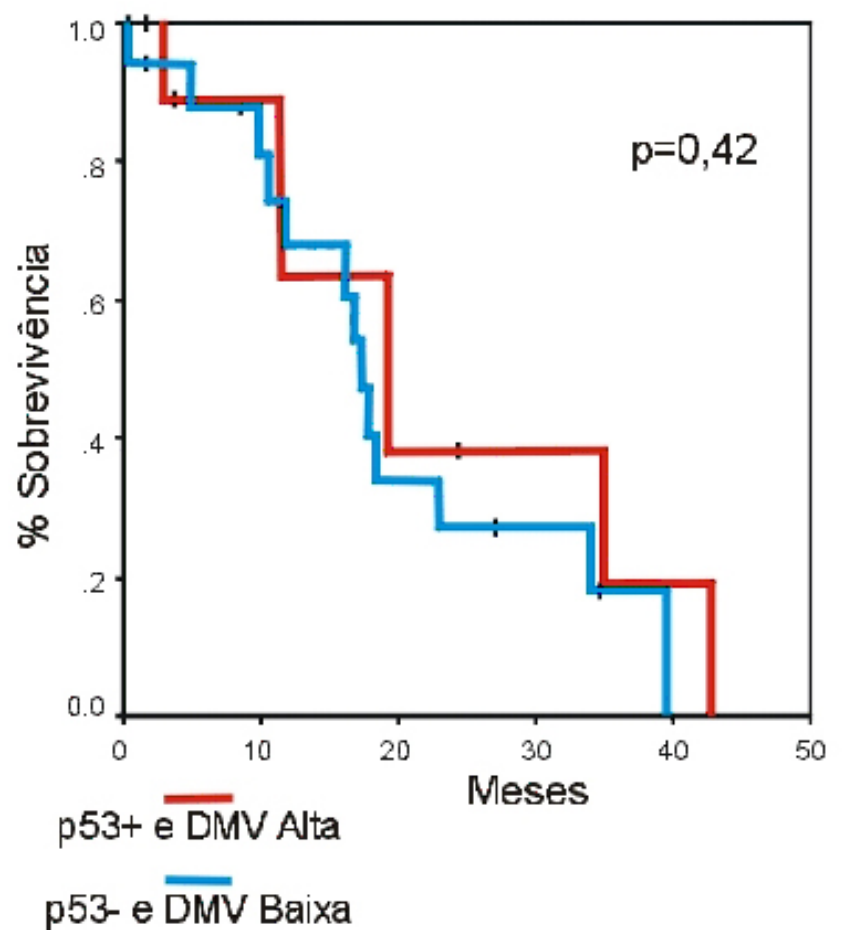

Gráfico 4: Curvas de sobrevivência pela combinação p53/DMV. 


\subsection{Análise da relação entre a densidade de microvasculatura e dados clínico-patológicos}

A média da DMV nos pacientes estudados foi de 46,2 vasos $/ \mathrm{mm}^{2}$. A DMV foi significativamente maior nos pacientes com tumores maiores que $3,0 \mathrm{~cm}(p=0,03)$. Nos pacientes com margem comprometida, também foi encontrado DMV maior $(p=0,04)$. A correlação entre a expressão do p53 com a DMV não foi estatisticamente significativa $(p=0,39)$.

Tabela 6 Relação da média da DMV com dados clínico-patológicos

\begin{tabular}{|c|c|c|c|c|}
\hline Variável & & n. pacientes & média DMV & $\mathrm{p}$ \\
\hline Total & & 49 & 46,2 & \\
\hline \multicolumn{5}{|l|}{ Idade } \\
\hline & $<52$ anos & $14(28,6 \%)$ & $47,9 \pm 16,9$ & 0,62 \\
\hline & $\geq 52$ anos & $35(71,4 \%)$ & $45,0 \pm 21,5$ & \\
\hline \multicolumn{5}{|l|}{ Sexo } \\
\hline & masculino & $22(44,9 \%)$ & $45,1 \pm 19,2$ & 0,71 \\
\hline & feminino & $27(45,1 \%)$ & $47,1 \pm 17,2$ & \\
\hline \multicolumn{5}{|c|}{$20(10,180)$} \\
\hline & $\mathrm{T} 1-2$ & $13(26,5 \%)$ & $49,4 \pm 19,8$ & 0,41 \\
\hline & $\mathrm{T} 3-4$ & $36(73,5 \%)$ & $44,7 \pm 17,6$ & \\
\hline \multicolumn{5}{|c|}{ (1), } \\
\hline & negativo & $20(40,8 \%)$ & $47,3 \pm 17,6$ & 0,18 \\
\hline & positivo & $29(59,2 \%)$ & $45,2 \pm 18,9$ & \\
\hline \multicolumn{5}{|l|}{ Tamanho } \\
\hline & $<3,0 \mathrm{~cm}$ & $20(40,8 \%)$ & $39,2 \pm 13,3$ & 0,03 \\
\hline & $\geq 3,0 \mathrm{~cm}$ & $29(59,2 \%)$ & $50,4 \pm 19,8$ & \\
\hline \multicolumn{5}{|c|}{ Grau Histológico } \\
\hline & bem $+\bmod$ & $42(85,7 \%)$ & $44,7 \pm 17,2$ & 0,09 \\
\hline & indiferenciado & $7(14,3 \%)$ & $55,3 \pm 12,5$ & \\
\hline \multicolumn{5}{|c|}{ 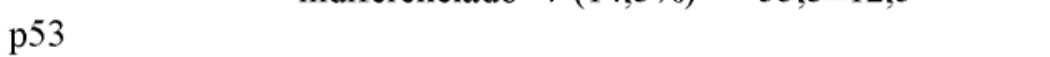 } \\
\hline & negativo & $29(59,2 \%)$ & $44,0 \pm 14,7$ & 0,39 \\
\hline & positivo & $20(40,8 \%)$ & $48,9 \pm 22,3$ & \\
\hline \multicolumn{5}{|c|}{ Invasão Vascular } \\
\hline & ausente & $23(46,9 \%)$ & $46,1 \pm 18,3$ & 0,99 \\
\hline & presente & $26(53,1 \%)$ & $46,2 \pm 18,4$ & \\
\hline margem & livre & $30(61,2 \%)$ & $42,5 \pm 15,6$ & 0.04 \\
\hline & comprometida & $19(39,8 \%)$ & $53,3 \pm 20,1$ & \\
\hline
\end{tabular}




\subsection{Análise multivariada}

Através da análise de modelo linear generalizado dos fatores clínicopatológicos significantes (margem e tamanho) listados na tabela 6, revelou-se que nessa casuística o único fator que apresentou relação independente com a DMV foi a margem cirúrgica. 


\section{DISCUSSÃO}

Nessa casuística, observou-se que a DMV média foi de 46,2 vasos $/ \mathrm{mm}^{2}$. A densidade da microvasculatura tumoral não foi preditiva da sobrevivência pós-operatória. Os pacientes com alta DMV apresentaram uma sobrevivência média de 20,7 meses e os de baixa DMV 17,9 meses $(P=0,60)$.

Alguns estudos conseguiram demonstrar uma relação entre a DMV e o prognóstico em pacientes portadores de adenocarcinoma pancreático (Giannopoulos et al., 2007; Stipa et al., 2002; Niedergethmann et al., 2002; Karademir et al., 2000; Ikeda et al.,1999; Itakura et al., 1997). Outros autores também demonstraram que a DMV está relacionada ao prognóstico em tumores de nasofaringe, ovário, mama, estômago, cólon e vias biliares (Guang-Wu et al., 2000; Labiche et al., 2009; Shivakumar et al., 2009; Konno et al., 2000; Dês Guetz et al., 2006.; Thelen et al., 2008).

Porém, no adenocarcinoma de pâncreas, a relação da alta DMV com o prognóstico não foi demonstrada em algumas séries (Ellis et al., 1998; Fujimoto et al., 1998; Ikeda et al., 1999; Takagi et al., 2005 e 2008). A razão dessa controvérsia pode ser, em parte, explicada por não haver uniformidade nos critérios de seleção dos pacientes, nas áreas de tumor avaliadas para 
contagem de vasos, no antígeno endotelial utilizado e técnicas de contagem dos microvasos (Takagi et al., 2008).

Não existe ainda, um método padronizado para a contagem da DMV. A metodologia escolhida para a realização do presente estudo foi a proposta por Weidner et al. (1991), que é amplamente utilizada da literatura. Nela, não é necessária a presença de um lúmen vascular ou a presença de hemácias para a contagem de um microvaso. Takagi et al., em 2008, consideraram importante a visualização do lúmen vascular para a definição da DMV tumoral e quando compararam o método tradicional com esse método modificado, observaram correlação com o prognóstico apenas no segundo grupo. Outros estudos comparativos são necessários para definir se essa metodologia é a mais adequada para a contagem da microvasculatura tumoral.

Também existe controvérsia quanto ao anticorpo escolhido para a coloração imunoistoquimíca do endotélio vascular (anticorpos anti-CD31, antiCD34 ou anti-fator VIII), o número de áreas contadas em cada secção tumoral (3-10 áreas) e a região do tumor a ser avaliada (periférica ou central e a que apresenta maior ou menor densidade de vasculatura) (Vermeulen, 1996).

A influência da escolha do anticorpo utilizado para coloração do endotélio dos microvasos não está bem definida. Os anticorpos anti-CD31 e 
anti-CD34 se ligam em igual intensidade ao endotélio de tecidos normais e tumorais. O anti-CD31 pode eventualmente corar células plasmáticas e o antiCD34 células estromais. Já o anticorpo anti-fator VIII tem uma sensibilidade menor ao endotélio tumoral. A reatividade desses anticorpos também pode ser alterada pela fixação do tecido tumoral em parafina. Atribui-se ao antiCD31 uma discreta vantagem nesse aspecto, porém a especificidade do antiCD34 é um pouco superior (Vermeulen et al., 1996). Takagi et al. (2008) não conseguiram obter boa coloração do endotélio vascular com o anticorpo antiCD34, apesar desse ser o anticorpo mais frequentemente utilizado (Tabela 7)

Tabela 7 Características de estudos da DMV no câncer de pâncreas

\begin{tabular}{llllllll}
\hline Autor & Ano & pacientes & anticorpo & $\begin{array}{l}\text { Número de } \\
\text { áreas contadas }\end{array}$ & $\begin{array}{l}\text { Técnica } \\
\text { contagem }\end{array}$ & $\begin{array}{l}\text { de } \\
\text { vasos } / \mathrm{mm}^{2}\end{array}$ \\
\hline Presente & 2008 & 49 & CD34 & 10 & Weidner & 46,2 \\
Takagi & 2008 & 41 & $\begin{array}{l}\text { CD34 } \\
\text { CD45 }\end{array}$ & 3 & Lúmem & \\
& & & $\begin{array}{l}\text { Fator } \\
\text { VIII }\end{array}$ & 5 & Weidner & $101^{*}$ \\
Espósito & 2004 & 137 & CD34 & 5 & Weidner & \\
Nakagawa & 2002 & 32 & CD34 & 5 & Weidner & $85^{*}$ \\
Niedergethmann & 2002 & 70 & CD34 & 5 & Weidner & $3,4 \#$ \\
Karademir & 2000 & 22 & Fator & 3 & Weidner & \\
Ikeda & 1999 & 40 & CD34 & 6 & Weidner & 30,1 \\
Fujimoto & 1998 & 50 & CD34 & 4 & Weidner & 44,9 \\
Ellis & 1998 & 22 & Fator & $?$ & & \\
\hline
\end{tabular}

*Somente avaliaram áreas hipervascularizadas da neoplasia \# vasos $/ \mathrm{mm}^{2} / \mathrm{mm}^{3}$ - vasos $/ \mathrm{mm}$ 
Sendo a angiogênese essencial para o crescimento tumoral e às metástases, é crucial que a medida da DMV tumoral seja padronizada e reprodutível. Não existe ainda, a padronização desse sistema de medida o que facilitaria a realização de futuros estudos comparativos.

Nesse trabalho utilizamos o anticorpo anti-CD34 e contamos 10 áreas aleatoriamente escolhidas na secção tumoral. Observou-se uma eficaz coloração do endotélio vascular e uma mínima parte dos microvasos contados não apresentava lúmen vascular. Utilizando-se 10 áreas de contagem em cada secção tumoral, minimizou-se as diferenças oriundas de heterogeneidades numa mesma secção. Ressalta-se que o presente estudo foi o que avaliou o maior número de áreas por secção, sendo que esse variou de 3 a 6 nos outros estudos (tabela 7 ).

A metodologia empregada foi eficaz para a identificação dos microvasos intratumorais. Obteve-se uma leitura da DMV média semelhante à DMV encontrada por outros autores que empregaram técnicas semelhantes (Fujimoto et al., 1988; Ellis et al., 1998).

Vários estudos avaliaram a DMV no adenocarcinoma pancreático e sugerem uma grande atividade angiogênica tumoral. Uma DMV tumoral significativamente superior à do tecido pancreático normal e na pancreatite crônica foi demonstrada (Kuehn et al. 1999; Espósito et al.2004). Outros 
estudos correlacionaram a DMV com o prognóstico pós-operatório no adenocarcinoma pancreático (Niedergethmann et al., 2002; Karademir et al., 1999; Stipa et al., 2002). Analisando 22 pacientes portadores de adenocarcinoma, Karademir et al. (1999) demonstraram que a densidade vascular na superfície tumoral e a DMV intratumoral estavam correlacionadas com a proliferação celular, com tumores mais indiferenciados e com tumores maiores que $3,0 \mathrm{~cm}$ além de menor sobrevivência. No presente estudo, demonstrou-se essa mesma associação da alta DMV, com os tumores maiores. Fujioka et al. (2001) também demonstraram que os pacientes com DMV alta apresentavam menor tempo livre de doença, menor sobrevivência geral e maior incidência de metástases hepáticas.

Em contrapartida, Ellis et al. (1998), não conseguiram demonstrar a relação da DMV/VEGF com sobrevivência e tempo livre de doença. Apesar disso, a grande maioria dos trabalhos indica que o adenocarcinoma de pâncreas apresenta um elevado grau de angiogênese como os tumores de mama (Uzzan et al. 2004), pulmão (Kadota et al. 2008), próstata (Kaygusuz et al.2007) e cólon (Dês Guetz, 2006). Em todos esses, a alta DMV está relacionada com o prognóstico e com um risco maior de desenvolvimento de metástases. O achado de maior DMV nos pacientes com margem comprometida da casuística estudada deve ser avaliado com precaução. Apesar de sugerir maior agressividade tumoral, como Giannopoulos et al (2007) demonstraram, não foi possível avaliar a proporção de pacientes com tumores no processo uncinado ou junto aos vasos mesentéricos. 
Outra explicação para os resultados no câncer de pâncreas serem conflitantes é que algumas casuísticas são constituídas de pacientes que já se encontram em uma fase avançada da doença. $O$ tempo de sobrevivência média pós-operatória não permite identificação de fatores prognósticos independentes. As curvas de sobrevivência apresentam um forte declive em ambos os braços e em um curto espaço de tempo. E a diferença entre elas ficam ainda menor quando a casuística é composta de um número pequeno de pacientes. Esse é o caso de estudos de tumores de alta malignidade como o câncer pancreático. Inúmeros trabalhos sobre fatores prognósticos no câncer pancreático não conseguem ser reproduzidos, apresentam resultados diferentes e fatores com baixa influência prognóstica (Takai et al., 2003, Wagner et al., 2004, Garcea et. al., 2005, Winter et al., 2006). Nas curvas de sobrevivência desse trabalho observa-se claramente esse comportamento (Gráficos 2, 3 e 4). Esforços para um diagnóstico precoce dessa patologia poderão contribuir para definir um melhor quais os fatores prognósticos mais significativos no câncer pancreático.

No estudo de Karademir et al. (2000), a casuística foi composta de $45,5 \%$ de pacientes no estadio 1 e foi possível demonstrar a influência prognóstica da DMV tumoral. No estudo de Ellis et al. (1998), não existe uma clara estratificação dos fatores clinico-patológicos da casuística, mas, observa-se uma sobrevida média de aproximadamente $50 \%$ em 60 meses e 
apenas o número de pacientes limitou a identificação da DMV como um fator preditor da sobrevivência. Já no estudo de Fujimoto et al. (1998), observa-se que $60 \%$ dos pacientes apresentam-se acima do estadio III e a expressão do VEGF e a DMV não foram fatores prognósticos.

Uma vez que a angiogênese é um importante evento na progressão do adenocarcinoma pancreático, há uma aparente contradição com a sua característica de hipovascularização na tomografia computadorizada com contraste endovenoso. Wang et al. (2003) ressaltaram que a atenuação do tumor pancreático é o resultado da combinação da DMV intra-tumoral, da desmoplasia e do tecido pancreático normal peritumoral que inclui, também, os vasos de maior calibre intra e peritumorais. Além disso, a perfusão do tecido tumoral depende da organização da drenagem venosa e linfática (linfangiogênese) que é significativamente desorganizada nas neoplasias (Jain et al., 1988; Cuenod et al., 2006; Kadota et al., 2008).

Uma das vantagens da análise da DMV é predizer o prognóstico. Porém, o conhecimento mais aprofundado da angiogênese tumoral pode permitir o delineamento de uma terapia mais efetiva. A inibição da angiogênese tornou-se um alvo de tratamento bastante atraente nos últimos anos, essa terapia oferece um benefício teórico de controle de crescimento tumoral e interação potencializadora da ação da quimio e da radioterapia. (Hess et al., 2001; Wildiers et al., 2003). 
Recentemente, terapias antiangiogênicas foram descritas (anticorpos anti-VEGF, anticorpos anti-receptor do VEGF e antisense). Com a aplicação do anticorpo monoclonal anti-receptor do VEGF - Bevacizumab observou-se a supressão do crescimento de tumores pancreáticos em estudos laboratoriais. Além disso, os tumores apresentaram uma melhor organização da microvasculatura e da perfusão do quimioterápico (Wildiers, 2003).

Infelizmente o estudo clínico de fase II (CALGB 80303) finalizado em 2008, não conseguiu demonstrar um real benefício na adição de Bevacizumab ao tratamento convencional (Gemcitabina e baixa dose de Cisplatina) em 52 pacientes com adenocarcinoma pancreático metastático. Os autores ressaltam a necessidade de identificar os pacientes que possuem mais chance de responder a terapia anti-angiogênica, evitando assim efeitos colaterais indesejáveis nos outros. Estudar a DMV tumoral antes da terapia pode ser uma maneira de identificar esses pacientes. Ainda não existem protocolos que incluam a análise da DMV como critério para aplicação de terapia anti-angiogênica.

Um benefício especial existe na análise desses alvos moleculares quando se intenciona aplicar quimioterapia neo-adjuvante. Apenas os pacientes com maior probabilidade de resposta seriam incluídos no tratamento e os pacientes nos quais se antevisse menor chance de resposta, 
não teriam seu tratamento cirúrgico definitivo postergado ou até impedido pela toxicidade do tratamento ou pela evolução tumoral.

O gene p53 foi extensamente investigado em vários tumores humanos sendo que, sua expressão normal regula a angiogênese através da indução da trombospondina-1, que é um forte inibidor da neovascularização em tumores de mama e cólon. A perda da função do gene p53 está associada a um aumento da angiogênese nessas neoplasias (Ren et al., 2006). As mutações no gene p53 levam a produção de uma proteína p53 mutada, que não consegue sofrer hidrólise enzimática normal e que se acumula no núcleo celular. Portanto, o resultado positivo da imunoistoquimica implica na identificação dos tumores com essa mutação.

O produto do gene p53 é uma fosfoproteína, primeiramente identificada em 1979, foi encontrada em pequenas quantidades nas células normais, mas em quantidades muito elevadas (5 a 100 vezes) nas células tumorais cultivadas em laboratório e, também, em tumores humanos. Os efeitos da proteína natural na proliferação celular incluem a regulação da transição da fase G-1 para a fase $S$ da mitose (como um ponto de checagem) e também determina a morte celular por apoptose (Hollstein et al., 1991; Volgelstein et al, 1992; Carlson e Lois, 1995, Lowe et al., 1994). Essas funções são mediadas pela interação da proteína p53 com sequências específicas da cadeia do DNA celular. Tal ligação permite a ação de outros genes no nível 
transcricional como os genes GADD45, MDM2 e p21Waf1/Cip1 (Kastan et al., 1992; Barak et al., 1993; Harper et al., 1993).

Assim, na presença de lesão do DNA, a proteína p53 natural acumulase e promove a expressão em cascata de outros genes e proteínas. Uma dessas é a proteína p21 que se liga a quinases dependentes de ciclina (CDK) e inibe sua atividade. Dessa forma o ciclo celular é interrompido antes da síntese do DNA danificado e é dada à célula a oportunidade de repará-lo. Caso a correção não ocorra satisfatoriamente, a presença da proteína p53 pode induzir a morte celular programada (apoptose) (Nelson et al., 1994; Hoffman et al., 1994; Hollstein et al., 1991).

Muitos quimioterápicos exercem sua ação antitumoral induzindo a apoptose das células tumorais. Assim, a positividade do p53 em tumores pancreáticos poderia influenciar a eficácia dessas drogas. Dong et al. (2003), Nio (2001) e Sinicrope (1996), relacionaram a expressão do p53 com a resposta à quimioterapia em câncer de pâncreas, porém não conseguiram demonstrar correlação com a sobrevivência.

Nessa casuística, observou-se que a coloração para p53 nuclear foi considerada positiva em 20 pacientes $(40,8 \%)$ e não foi preditiva da sobrevivência pós-operatória. Os pacientes p53 negativos apresentaram uma sobrevivência média de 19 meses e os p53 positivos 19,3 meses $(p=0,71)$. A 
proporção de pacientes com análise imunoistoquímica positiva assemelha-se ao achado de todos os autores que estudaram tumores pancreáticos, situando-se a positividade entre $35 \%$ e $69,5 \%$ (Garcea et al., 2005). A correlação com a sobrevivência somente foi demonstrada em $18 \%$ desses estudos. A razão desses resultados em parte pode ser explicada porque a ausência da expressão do p53 não é sempre sinônima de sua função normal (deleções) (Jureidini et al., 2003).

Hu et al. (1999) e Nio et al. (1998) demonstraram que a expressão do gene p53 somente foi relacionada à sobrevivência, quando estava associada à expressão de $\mathrm{Bcl}-2$ e p21, respectivamente. Atualmente, pode-se dizer que as mutações isoladas do p53 não oferecem informações prognósticas no adenocarcinoma pancreático, mas podem ser utilizadas em casos selecionados para predizer a resposta à terapia citotóxica (Garcea et al., 2005).

É necessário cautela na análise estatística dos dados obtidos, em decorrência do número da amostragem utilizada. O número da amostragem limita a análise das diferenças entre as curvas de sobrevivência e das diferenças entre os dados clínico-patológicos. O erro padrão é diretamente proporcional ao desvio padrão e inversamente proporcional à raiz quadrada do número da amostra. Assim, quanto maior o desvio padrão e menor o número da amostra, maior será o erro padrão. 
Na análise da média da DMV nos pacientes p53 negativos ou positivos da casuística estudada, uma amostragem maior e menos heterogênea (poucos indivíduos com DMV muito diferente da média - alto desvio padrão) poderia evidenciar que os pacientes p53 negativos possuem menor DMV que os p53 positivos e assim, demonstrar o efeito regulador da expressão do p53 na angiogênese do adenocarcinoma pancreático. Já na análise dos pacientes com tumores indiferenciados, o baixo número de casos não permitiu diferença estatística significativa.

Nos últimos anos, importantes avanços foram feitos no tratamento do câncer pancreático. Esquemas de quimioterapia adjuvante baseados em agentes citotóxicos como Gemcitabina, Oxaliplatina, Capecitabina e Irinotecan foram desenvolvidos e, a análise dos benefícios da aplicação de terapias dirigidas a alvos moleculares como os inibidores do receptor do fator de crescimento epidérmico (EGFR) e VEGF estão sendo realizadas.

A associação desses resultados com os dados de investigação na área da biologia molecular poderá predizer com maior exatidão o prognóstico e definir novas estratégias no tratamento do câncer pancreático. 


\section{CONCLUSÕES}

Nas condições do presente estudo pode-se concluir:

A densidade de microvasculatura e a expressão do gene p53 não foram fatores preditivos da sobrevivência pós-operatória.

Não há evidencia do papel do gene p53 no controle da angiogênese no câncer do pâncreas.

Existe maior densidade de microvasculatura nos pacientes com tumores maiores de 3,0cm e, cuja margem cirúrgica estava comprometida, sendo esse o único fator com relação independente. 


\section{REFERÊNCIAS BIBLIOGRÁFICAS}

Albo D, Farrow B, Berger DH. Translation of recent advances and discoveries in molecular biology and immunology in the diagnosis and treatment of pancreatic cancer. Surg Oncol Clin N Am. 2008;17(2):357-76.

Alexakis N, Halloran C, Raraty M, Ghaneh P, Sutton R, Neoptolemos JP. Current standards of surgery for pancreatic cancer. $\mathrm{Br} J$ Surg. 2004;91(11):1410-27.

Bacchella T. Duodenopancreatectomia parcial: reconstrução com duas alças jejunais isoladas, resultados imediatos. São Paulo, 1986. Tese (Doutorado). Faculdade de Medicina da Universidade de São Paulo.

Baker $\mathrm{CH}$, Solorzano CC, Fidler IJ. Angiogenesis and cancer metastasis: antiangiogenic therapy of human pancreatic adenocarcinoma. Int J Clin Oncol. 2001;6(2):59-65.

Banks L, Matlashewski G, Crawford L. Isolation of human-p53-specific monoclonal antibodies and their use in the studies of human p53 expression. Eur J Biochem. 1986;159(3):529-34.

Barak $\mathrm{Y}$, Juven $\mathrm{T}$, Haffner $\mathrm{F}$; mdm2 expression is induced by wild type p53 activity. Embo J 12:468, 1993

Bertheau P, Espié M, Turpin E, Lehmann J, Plassa LF, Varna M, et al. TP53 status and response to chemotherapy in breast cancer. Pathobiology. 2008;75(2):132-9.

Bertheau P, Plassa F, Espié M, Turpin E, de Roquancourt A, Marty M, et al Effect of mutated TP53 on response of advanced breast cancers to high-dose chemotherapy. Lancet. 2002;360(9336):852-4.

Bertheau P, Turpin E, Rickman DS, Espié M, de Reyniès A, Feugeas JP, et al. Exquisite sensitivity of TP53 mutant and basal breast cancers to a dosedense epirubicin-cyclophosphamide regimen. PLoS Med. 2007;4(3):e90.

Bilimoria KY, Bentrem DJ, Ko CY, Ritchey J, Stewart AK, Winchester DP, et al. Validation of the 6th edition AJCC Pancreatic Cancer Staging System: report from the National Cancer Database. Cancer. 2007;110(4):738-44. 
Bonnefoi $\mathrm{H}$, de Cremoux $\mathrm{P}$. [New predictive factors for chemosensitivity of breast cancers]. Bull Cancer. 2008;95(10):943-50.

Brasil. Ministério da Saúde. Instituto Nacional de Atenção à Saúde. Instituto Nacional do Câncer. Estimativas 2008: incidência de câncer no Brasil. Rio de Janeiro; 2007.(disponível em http://www.inca.gov.br/estimativa/2008/ Acessado em 05/05/2009)

Cao D, Zhang Q, Wu LS, Salaria SN, Winter JW, Hruban RH, et al. Prognostic significance of maspin in pancreatic ductal adenocarcinoma: tissue microarray analysis of 223 surgically resected cases. Mod Pathol. 2007;20(5):570-8.

Carson DA, Lois A; Cancer progression and p53. Lancet 346:1009-1011, 1995.

Cascalló M, Calbó J, Capellà G, Fillat C, Pastor-Anglada M, Mazo A. Enhancement of gemcitabine-induced apoptosis by restoration of p53 function in human pancreatic tumors. Oncology. 2005;68(2-3):179-89.

Chua YJ, Cunningham D. Adjuvant treatment for resectable pancreatic cancer. J Clin Oncol. 2005;23(20):4532-7.

Cress RD, Yin D, Clarke L, Bold R, Holly EA. Survival among patients with adenocarcinoma of the pancreas: a population-based study (United States). Cancer Causes Control. 2006;17(4):403-9.

Dameron KM, Volpert OV, Tainsky MA, Bouck N. Control of angiogenesis in fibroblasts by p53 regulation of thrombospondin-1. Science. 1994;265(5178):1582-4.

Del Chiaro M, Boggi U, Presciuttini S, Bertacca L, Croce C, Mosca I, et al. Genetics of pancreatic cancer: where are we now? Where are we going? JOP. 2005;6(1 Suppl):60-7.

Deniz H, Karakök M, Yagcı F, Güldür ME. Evaluation of relationship between HIF-1alpha immunoreactivity and stage, grade, angiogenic profile and proliferative index in bladder urothelial carcinomas. Int Urol Nephrol. 2009 May 30. doi: 10.1007/s11255-009-9590-5.

Des Guetz G, Uzzan B, Nicolas P, Cucherat M, Morere JF, Benamouzig R, et al. Microvessel density and VEGF expression are prognostic factors in colorectal cancer. Meta-analysis of the literature. $\mathrm{Br} J$ Cancer. 2006;94(12):1823-32. 
Diener MK, Heukaufer C, Schwarzer G, Seiler CM, Antes G, Buchler MW, et al. Pancreaticoduodenectomy (classic Whipple) versus pylorus-preserving pancreaticoduodenectomy ( $\mathrm{pp}$ Whipple) for surgical treatment of periampullary and pancreatic carcinoma. Cochrane Database Syst Rev. 2008 Apr 16;(2): CD006053

Diener MK, Knaebel HP, Heukaufer C, Antes G, Büchler MW, Seiler CM. A systematic review and meta-analysis of pylorus-preserving versus classical pancreaticoduodenectomy for surgical treatment of periampullary and pancreatic carcinoma. Ann Surg. 2007;245(2):187-200.

Dong M, Ma G, Tu W, Guo KJ, Tian YL, Dong YT. Clinicopathological significance of $\mathrm{p} 53$ and $\mathrm{mdm} 2$ protein expression in human pancreatic cancer. World J Gastroenterol. 2005;11(14):2162-5.

Ellis LM, Takahashi Y, Fenoglio CJ, Cleary KR, Bucana CD, Evans DB. Vessel counts and vascular endothelial growth factor expression in pancreatic adenocarcinoma. Eur J Cancer. 1998;34(3):337-40.

Esposito I, Kleeff J, Bergmann F, Reiser C, Herpel E, Friess H, et al. Most pancreatic cancer resections are R1 resections. Ann Surg Oncol. 2008;15(6):1651-60.

Esposito I, Menicagli M, Funel N, Bergmann F, Boggi U, Mosca F, et al. Inflammatory cells contribute to the generation of an angiogenic phenotype in pancreatic ductal adenocarcinoma. J Clin Pathol. 2004;57(6):630-6.

Ficari F, Cama A, Valanzano R, Curia MC, Palmirotta R, Aceto G, Esposito DL, Crognale S, Lombardi A, Messerini L, Mariani-Costantini R, Tonelli F, Battista P. APC gene mutations and colorectal adenomatosis in familial adenomatous polyposis. Br J Cancer. 2000;82(2):348-53.

Folkman J, Watson K, Ingber D, Hanahan D. Induction of angiogenesis during the transition from hyperplasia to neoplasia. Nature. 1989;339(6219):58-61.

Folkman J. The role of angiogenesis in tumor growth. Semin Cancer Biol. 1992;3(2):65-71.

Folkman $\mathrm{J}$. What is the evidence that tumors are angiogenesis dependent? $\mathrm{J}$ Natl Cancer Inst. 1990;82(1):4-6. 
Fujimoto K, Hosotani R, Wada M, Lee JU, Koshiba T, Miyamoto Y, Tsuji S, Nakajima $S$, Doi $R$, Imamura $M$. Expression of two angiogenic factors, vascular endothelial growth factor and platelet-derived endothelial cell growth factor in human pancreatic cancer, and its relationship to angiogenesis. Eur $\mathrm{J}$ Cancer. 1998;34(9):1439-47.

Fujioka S, Yoshida K, Yanagisawa S, Kawakami M, Aoki T, Yamazaki Y. Angiogenesis in pancreatic carcinoma: thymidine phosphorylase expression in stromal cells and intratumoral microvessel density as independent predictors of overall and relapse-free survival. Cancer. 2001;92(7):1788-97

Garcea G, Neal CP, Pattenden CJ, Steward WP, Berry DP. Molecular prognostic markers in pancreatic cancer: a systematic review. Eur J Cancer. 2005;41(15):2213-36.

Gasparini G, Bonoldi E, Viale G, Verderio P, Boracchi P, Panizzoni GA, et al. Prognostic and predictive value of tumour angiogenesis in ovarian carcinomas. Int J Cancer. 1996;69(3):205-11.

Gasparini G, Harris AL. Clinical importance of the determination of tumor angiogenesis in breast carcinoma: much more than a new prognostic tool. $\mathrm{J}$ Clin Oncol. 1995;13(3):765-82.

Gasparini G, Weidner N, Maluta S, Pozza F, Boracchi P, Mezzetti M, et al. Intratumoral microvessel density and p53 protein: correlation with metastasis in head-and-neck squamous-cell carcinoma. Int J Cancer. 1993;55(5):739-44.

Giannopoulos G, Kavantzas N, Parasi A, Tiniakos D, Peros G, Tzanakis N, Patsouris E, Pavlakis K. Morphometric microvascular characteristics in the prognosis of pancreatic and ampullary carcinoma. Pancreas. 2007;35(1):4752.

Giovannetti E, Mey V, Nannizzi S, Pasqualetti G, Del Tacca M, Danesi R. Pharmacogenetics of anticancer drug sensitivity in pancreatic cancer. Mol Cancer Ther. 2006;5(6):1387-95.

Grem JL, Voeller DM, Geoffroy F, Horak E, Johnston PG, Allegra CJ. Determinants of trimetrexate lethality in human colon cancer cells. $\mathrm{Br} \mathrm{J}$ Cancer. 1994;70(6):1075-84. 
Guang-Wu H, Sunagawa M, Jie-En L, Shimada S, Gang Z, Tokeshi Y, Kosugi $\mathrm{T}$. The relationship between microvessel density, the expression of vascular endothelial growth factor (VEGF), and the extension of nasopharyngeal carcinoma.Laryngoscope. 2000;110(12):2066-9.

Hait WN, Yang JM. The individualization of cancer therapy: the unexpected role of p53. Trans Am Clin Climatol Assoc. 2006;117:85-101.

Harper JW, Adami GR, Wei N; The p21 Cdk-interacting protein Clip1 is a potent inhibitor of G1 cyclin-dependant kinases. Cell 75:805816, 1993.

Hashimoto K, Nio Y, Koike M, Itakura M, Yano S, Higami T, et al. Expression of retinoblastoma and p53 pathway-related proteins in resectable invasive ductal carcinoma of the pancreas: potential cooperative effects on clinical outcome. Anticancer Res. 2005;25(2B):1361-8.

Hess C, Vuong V, Hegyi I, Riesterer O, Wood J, Fabbro D, et al. Effect of VEGF receptor inhibitor PTK787/ZK222584 [correction of ZK222548] combined with ionizing radiation on endothelial cells and tumour growth. $\mathrm{Br} \mathrm{J}$ Cancer. 2001;85(12):2010-6.

Higashiyama M, Kodama K, Yokouchi H, Takami K, Doi O, Kobayashi H, et al. Immunohistochemical p53 protein status in nonsmall cell lung cancer is a promising indicator in determining in vitro chemosensitivity to some anticancer drugs. J Surg Oncol. 1998;68(1):19-24.

Hirota M, Shimada S, Yamamoto K, Tanaka E, Sugita H, Egami H, et al. Pancreatectomy using the no-touch isolation technique followed by extensive intraoperative peritoneal lavage to prevent cancer cell dissemination: a pilot study. JOP. 2005;6(2):143-51.

Hochster HS, Haller DG, de Gramont A, Berlin JD, Philip PA, Moore MJ, et al. Consensus report of the international society of gastrointestinal oncology on therapeutic progress in advanced pancreatic cancer. Cancer. 2006;107(4):676-85.

Hoffmann TK, Sonkoly E, Hauser U, van Lierop A, Whiteside TL, Klussmann $\mathrm{JP}$, et al. Alterations in the p53 pathway and their association with radio- and chemosensitivity in head and neck squamous cell carcinoma. Oral Oncol. 2008;44(12):1100-9.

Hollstein M, Sidransky D, Vogelstein B, Harris CC. p53 mutations in human cancers. Science. 1991;253(5015):49-53. 
Hosaka N, Ichikawa Y, Ishikawa T, Nagashima Y, Kunisaki C, Takahashi M, et al. Correlation of immunohistochemical p53 labeling index with inhibition rate in chemosensitivity test in gastric and colon cancer. Anticancer Res. 2001;21(1A):229-35.

Howard TJ, Krug JE, Yu J, Zyromski NJ, Schmidt CM, Jacobson LE, et al. A margin-negative R0 resection accomplished with minimal postoperative complications is the surgeon's contribution to long-term survival in pancreatic cancer. J Gastrointest Surg. 2006;10(10):1338-45.

Hu YX, Watanabe H, Ohtsubo K, Yamaguchi Y, Ha A, Motoo Y, Okai T, Sawabu N. Bcl-2 expression related to altered p53 protein and its impact on the progression of human pancreatic carcinoma. $\mathrm{Br} \mathrm{J}$ Cancer. 1999 Jun;80(7):1075-9.

Ikeda N, Adachi M, Taki T, Huang C, Hashida H, Takabayashi A, Sho M, Nakajima $\mathrm{Y}$, Kanehiro $\mathrm{H}$, Hisanaga M, Nakano $\mathrm{H}$, Miyake M. Prognostic significance of angiogenesis in human pancreatic cancer. $\mathrm{Br} \mathrm{J}$ Cancer. 1999;79(9-10):1553-63.

Ikeguchi M, Saito H, Katano K, Gomyo Y, Tsujitani S, Maeta M, et al. Relationship between the long-term effects of intraperitoneal chemotherapy and the expression of p53 and p21 in patients with gastric carcinoma at stage IIla and stage IIlb. Int Surg. 1997;82(2):170-4.

Itakura J, Ishiwata $\mathrm{T}$, Friess $\mathrm{H}$, Fujii $\mathrm{H}$, Matsumoto $\mathrm{Y}$, Büchler MW, Korc M. Enhanced expression of vascular endothelial growth factor in human pancreatic cancer correlates with local disease progression. Clin Cancer Res. 1997;3(8):1309-16.

Itaya M, Yoshimoto J, Kojima K, Futagawa S. Usefulness of p53 protein, Bcl-2 protein and $\mathrm{Ki}-67$ as predictors of chemosensitivity of malignant tumors. Oncol Rep. 1999;6(3):675-82.

Itaya M, Yoshimoto J, Kojima K, Kawasaki S. Immunohistochemistry of p53, $\mathrm{Bcl}-2$, and $\mathrm{Ki}-67$ as predictors of chemosensitivity. Methods Mol Med. 2005;110:213-27.

Japan Pancreas Society. Classification of Pancreatic Carcinoma. English edition. Tokyo: Kanehara \& Co; 1996.

Jemal A, Siegel R, Ward E, Murray T, Xu J, Thun MJ. Cancer statistics, 2007. CA Cancer J Clin. 2007;57(1):43-66. 
Jureidini R. Influência da expressão do gene p53 na resposta à quimioterapia FAM para o carcinoma gástrico avançado. ABCD,. 2003; 16(4):153-8.

Kadota K, Huang CL, Liu D, Ueno M, Kushida Y, Haba R. The clinical significance of lymphangiogenesis and angiogenesis in non-small cell lung cancer patients. Eur J Cancer. 2008;44(7):1057-1067.

Karademir S, Sökmen S, Terzi C, Sağol O, Ozer E, Astarcioğlu H, et al. Tumor angiogenesis as a prognostic predictor in pancreatic cancer. J Hepatobiliary Pancreat Surg. 2000;7(5):489-495.

Kastan MB, Zhan QM, Eldeiry WS; A mammalian cell cycke checkpoint pathway utilizing p53 and GADD $\$ \%$ is defective in ataxiatelangiectasia. Cell 71:587-597, 1992.

Kawarada Y. [JPS 5th ed. Classification of pancreatic cancer and JPS classification versus UICC classification]. Nippon Rinsho. 2006;64 Suppl 1:8186.

Kaygusuz G, Tulunay O, Baltaci S, Gogus O. Microvessel density and regulators of angiogenesis in malignant and nonmalignant prostate tissue. Int Urol Nephrol. 2007;39(3):841-850

Kikuyama S, Inada T, Shimizu K, Miyakita M, Ogata Y. p53, bcl-2 and thymidine phosphorylase as predictive markers of chemotherapy in patients with advanced and recurrent gastric cancer. Anticancer Res. 2001;21(3C):2149-2153.

Kim YJ, Seo DW, Pack KM, Jeong E, Kim SC, Han DJ, et al. [The prognostic factors of pancreatic cancer can be different according to clinical stages]. Korean J Gastroenterol. 2008;51(3):181-9.

Klöppel G, Solcia E, Longnecker DS, Capella C, Sobin LH; Histopatological typing of tumors of the exocrine pancreas, 2 ed. World Health Org. Springer, Berlim, 1996.

Ko AH, Dito E, Schillinger B, Venook AP, Xu Z, Bergsland EK, et al. A phase II study evaluating bevacizumab in combination with fixed-dose rate gemcitabine and low-dose cisplatin for metastatic pancreatic cancer: is an anti-VEGF strategy still applicable? Invest New Drugs. 2008;26(5):463-71. 
Konno H, Baba M, Tanaka T, Kamiya K, Ota M, Oba K, Shoji A, Kaneko T, Nakamura S. Overexpression of vascular endothelial growth factor is responsible for the hematogenous recurrence of early-stage gastric carcinoma. Eur Surg Res. 2000;32(3):177-81.

Koorstra JB, Hustinx SR, Offerhaus GJ, Maitra A. Pancreatic carcinogenesis. Pancreatology. 2008;8(2):110-25.

Kudrimoti M, Lee EY, Kang Y, Ahmed M, Mohiuddin M. Genetic markers predictive of response to induction chemoradiotherapy for locally advanced rectal cancers. J Ky Med Assoc. 2007;105(1):18-22.

Kuehn R, Lelkes PI, Bloechle C, Niendorf A, Izbicki JR. Angiogenesis, angiogenic growth factors, and cell adhesion molecules are upregulated in chronic pancreatic diseases: angiogenesis in chronic pancreatitis and in pancreatic cancer. Pancreas. 1999;18(1):96-103.

Labiche A, Elie N, Herlin P, Denoux Y, Crouet H, Heutte N, et al. Prognostic significance of tumour vascularisation on survival of patients with advanced ovarian carcinoma. Histol Histopathol. 2009;24(4):425-35.

Lehmann-Che J, Turpin E, Bertheau $P$, Espié $M$, de Thé $H$. [Exquisite sensitivity of TP53 mutant breast cancers to dose-dense chemotherapy]. Med Sci (Paris). 2007;23(11):1021-3.

Liotta LA, Steeg PS, Stetler-Stevenson WG. Cancer metastasis and angiogenesis: an imbalance of positive and negative regulation. Cell. 1991;64(2):327-36.

Lowe SW, Bodis S, McClatchey A, Remington L, Ruley HE, Fisher DE, et al. p53 status and the efficacy of cancer therapy in vivo. Science. 1994;266(5186):807-10.

Lowe SW, Ruley HE, Jacks T, Housman DE; p53-dependent apoptosis modulates the cytotoxity of anticancer agents. Cell 74: 957-967, 1993.

Lygidakis NJ, Jain S, Sacchi M, Vrachnos P. Adenocarcinoma of the pancreas--past, present and future. Hepatogastroenterology. 2005;52(64):1281-92.

Macchiarini P, Fontanini G, Hardin MJ, Squartini F, Angeletti CA. Relation of neovascularisation to metastasis of non-small-cell lung cancer. Lancet. 1992;340(8812):145-6. 
Mäkinen K, Hakala T, Lipponen P, Alhava E, Eskelinen M. Clinical contribution of bcl-2, p53 and Ki-67 proteins in pancreatic ductal adenocarcinoma. Anticancer Res. 1998;18(1B):615-8.

Marion-Audibert AM, Barel C, Gouysse G, Dumortier J, Pilleul F, Pourreyron $\mathrm{C}$, et al. Low microvessel density is an unfavorable histoprognostic factor in pancreatic endocrine tumors. Gastroenterology. 2003;125(4):1094-104.

Michalski CW, Kleeff J, Wente MN, Diener MK, Büchler MW, Friess H. Systematic review and meta-analysis of standard and extended lymphadenectomy in pancreaticoduodenectomy for pancreatic cancer. $\mathrm{Br} \mathrm{J}$ Surg. 2007;94(3):265-73.

Michalski CW, Weitz J, Büchler MW. Surgery insight: surgical management of pancreatic cancer. Nat Clin Pract Oncol. 2007;4(9):526-35.

Mohseni MG, Mohammadi A, Heshmat AS, Kosari F, Meysamie AP. The lack of correlation between mast cells and microvessel density with pathologic feature of renal cell carcinoma. Int Urol Nephrol. 2009. doi: 10.1007/s11255009-9577-2.

Mukhopadhyay D, Tsiokas L, Sukhatme VP. Wild-type p53 and v-Src exert opposing influences on human vascular endothelial growth factor gene expression. Cancer Res. 1995;55(24):6161-5.

Müller M, Schleithoff ES, Stremmel W, Melino G, Krammer PH, Schilling T. One, two, three--p53, p63, p73 and chemosensitivity. Drug Resist Updat. 2006;9(6):288-306.

Nelson WG, Kastan MB: DNA strand breaks: the DNA template alterations that trigger p53-dependent DNA damage response pathways. Mol Cell Biol 14: 1815-1823, 1994.

Neoptolemos JP, Stocken DD, Dunn JA, Almond J, Beger HG, Pederzoli P, et al. Influence of resection margins on survival for patients with pancreatic cancer treated by adjuvant chemoradiation and/or chemotherapy in the ESPAC-1 randomized controlled trial. Ann Surg. 2001;234(6):758-68.

Neoptolemos JP, Stocken DD, Friess H, Bassi C, Dunn JA, Hickey H, et al. A randomized trial of chemoradiotherapy and chemotherapy after resection of pancreatic cancer. N Engl J Med. 2004 Mar 18;350(12):1200-10. Erratum in: N Engl J Med. 2004;351(7):726. 
Neubauer H, Gall C, Vogel U, Hornung R, Wallwiener D, Solomayer E, et al. Changes in tumour biological markers during primary systemic chemotherapy (PST). Anticancer Res. 2008;28(3B):1797-804.

Niedergethmann M, Hildenbrand R, Wostbrock B, Hartel M, Sturm JW, Richter A, et al. High expression of vascular endothelial growth factor predicts early recurrence and poor prognosis after curative resection for ductal adenocarcinoma of the pancreas. Pancreas. 2002;25(2):122-9.

Nio Y, Dong M, Iguchi C, Yamasawa K, Toga T, Itakura M, et al. Expression of Bcl-2 and p53 protein in resectable invasive ductal carcinoma of the pancreas: effects on clinical outcome and efficacy of adjuvant chemotherapy. J Surg Oncol. 2001;76(3):188-96.

Nio Y, Dong M, Uegaki K, Hirahara N, Minari Y, Sasaki S, Takamura M, Iguchi C, Tamura K. p53 expression affects the efficacy of adjuvant chemotherapy after resection of invasive ductal carcinoma of the pancreas. Anticancer Res. 1998;18(5B):3773-9.

Nishiyama $\mathrm{H}$, Watanabe $\mathrm{J}$, Ogawa $\mathrm{O}$. p53 and chemosensitivity in bladder cancer. Int J Clin Oncol. 2008;13(4):282-6.

Oettle H, Post S, Neuhaus P, Gellert K, Langrehr J, Ridwelski K, et al. Adjuvant chemotherapy with gemcitabine vs observation in patients undergoing curative-intent resection of pancreatic cancer: a randomized controlled trial. JAMA. 2007;297(3):267-77.

Parikh AA, Johnson JC, Merchant NB. Genomics and proteomics in predicting cancer outcomes. Surg Oncol Clin N Am. 2008;17(2):257-77, vii.

Perini MV. Estudos dos fatores clinico-patológicos no prognóstico de pacientes submetidos à ressecção de adenocarcinoma pancreático. São Paulo, 2005. Dissertação (Mestrado em Ciências) - Faculdade de Medicina da Universidade de São Paulo, São Paulo, 2005.

Pollock R. (ed.) UICC manual de oncologia clínica. $8^{a}$ ed. São Paulo: Fundação Oncocentro de São Paulo; 2006. p. 468.

Raut CP, Tseng JF, Sun CC, Wang H, Wolff RA, Crane CH, et al. Impact of resection status on pattern of failure and survival after pancreaticoduodenectomy for pancreatic adenocarcinoma. Ann Surg. 2007;246(1):52-60. 
Reiher F, Ozer O, Pins M, Jovanovic BD, Eggener S, Campbell SC. p53 and microvessel density in primary resection specimens of superficial bladder cancer. J Urol. 2002;167(3):1469-74.

Ren B, Yee KO, Lawler J, Khosravi-Far R. Regulation of tumor angiogenesis by thrombospondin-1. Biochim Biophys Acta. 2006;1765(2):178-88.

Ribeiro U Jr, Finkelstein SD, Safatle-Ribeiro AV, Landreneau RJ, Clarke MR, Bakker A, et al. p53 sequence analysis predicts treatment response and outcome of patients with esophageal carcinoma. Cancer.1998;83(1):7-18.

Richter A, Niedergethmann M, Sturm JW, Lorenz D, Post S, Trede M. Longterm results of partial pancreaticoduodenectomy for ductal adenocarcinoma of the pancreatic head: 25-year experience. World J Surg. 2003;27(3):324-9.

Rosner B. Fundamentals of biostatistics. $4^{\mathrm{a}}$ ed. New York: Duxbury Press; 1994. p. 682.

Saif MW. Anti-angiogenesis therapy in pancreatic carcinoma. JOP. 2006. 9;7(2):163-73.

Saif MW. Controversies in the adjuvant treatment of pancreatic adenocarcinoma. JOP. 2007;8(5):545-52.

Saif MW. Pancreatic cancer: is this bleak landscape finally changing? Highlights from the '43rd ASCO Annual Meeting'. Chicago, IL, USA. June 1-5, 2007. JOP. 2007;8(4):365-73.

Schmidt CM, Powell ES, Yiannoutsos CT, Howard TJ, Wiebke EA, Wiesenauer CA, et al. Pancreaticoduodenectomy: a 20-year experience in 516 patients. Arch Surg. 2004;139(7):718-25.

Schneider G, Hamacher R, Eser S, Friess H, Schmid RM, Saur D. Molecular biology of pancreatic cancer--new aspects and targets. Anticancer Res. 2008;28(3A):1541-50.

Schneider G, Schmid RM. Genetic alterations in pancreatic carcinoma. Mol Cancer. 2003;2:15.

Schnelldorfer T, Ware AL, Sarr MG, Smyrk TC, Zhang L, Qin R, et al. Longterm survival after pancreatoduodenectomy for pancreatic adenocarcinoma: is cure possible? Ann Surg. 2008;247(3):456-62. 
Shears LL, Ribeiro U, Kane J, Safatle-Ribeiro A, Watkins S, Posner M. Apoptosis in esophageal cancer following induction chemoradiotherapy. J Surg Res. 1998;79(1):20-4.

Shivakumar S, Prabhakar BT, Jayashree K, Rajan MG, Salimath BP. Evaluation of serum vascular endothelial growth factor (VEGF) and microvessel density (MVD) as prognostic indicators in carcinoma breast. J Cancer Res Clin Oncol. 2009;135(4):627-36.

Sinicrope FA, Evans DB, Leach SD, Cleary KR, Fenoglio CJ, Lee JJ, Abbruzzese JL. bcl-2 and p53 expression in resectable pancreatic adenocarcinomas: association with clinical outcome. Clin Cancer Res. 2(12):2015-22.1996.

Sinicrope FA, Roddey G, McDonnell TJ, Shen Y, Cleary KR, Stephens LC. Increased apoptosis accompanies neoplastic development in the human colorectum.Clin Cancer Res. 1996;2(12):1999-2006.

Smeenk HG, Tran TC, Erdmann J, van Eijck CH, Jeekel J. Survival after surgical management of pancreatic adenocarcinoma: does curative and radical surgery truly exist? Langenbecks Arch Surg. 2005 Apr;390(2):94-103.

Sosa JA, Bowman HM, Gordon TA, Bass EB, Yeo CJ, et al. Importance of hospital volume in the overall management of pancreatic cancer. Ann Surg. 1998;228(3):429-38.

Soussi T, Asselain B, Hamroun D, Kato S, Ishioka C, Claustres M, et al. Metaanalysis of the p53 mutation database for mutant p53 biological activity reveals a methodologic bias in mutation detection. Clin Cancer Res. 2006;12(1):62-9.

Stellmach V, Volpert OV, Crawford SE, Lawler J, Hynes RO, Bouck N. Tumour suppressor genes and angiogenesis: the role of TP53 in fibroblasts. Eur J Cancer. 1996;32A(14):2394-400.

Stipa F, Lucandri G, Limiti MR, Bartolucci P, Cavallini M, Di Carlo V, et al. Angiogenesis as a prognostic indicator in pancreatic ductal adenocarcinoma. Anticancer Res. 2002;22(1A):445-9.

Sultana A, Neoptolemos J, Ghaneh P. Adjuvant treatment. HPB (Oxford). 2006;8(5):352-64.

Tahara E. New approaches to cancer therapy an prevention. Cancer. 1996;77(Suppl 8):1758. 
Taii A, Hamada S, Kataoka K, Yasukawa S, Sonoyama T, Okanoue T, et al. Correlations between p53 gene mutations and histologic characteristics of pancreatic ductal carcinoma. Pancreas. 2009;38(2):e60-7.

Takagi K, Takada T, Amano H, Yoshida M, Miura H, Toyota N, et al. Analysis of microvessels in pancreatic cancer: by light microscopy, confocal laser scan microscopy, and electron microscopy. J Hepatobiliary Pancreat Surg. 2008;15(4):384-90.

Takagi K, Takada T, Amano H. A high peripheral microvessel density count correlates with a poor prognosis in pancreatic cancer. J Gastroenterol. 2005;40(4):402-8.

Takai S, Satoi S, Toyokawa H, Yanagimoto H, Sugimoto N, Tsuji K, et al. Clinicopathologic evaluation after resection for ductal adenocarcinoma of the pancreas: a retrospective, single-institution experience. Pancreas. 2003;26(3):243-9.

Talar-Wojnarowska R, Gasiorowska A, Smolarz B, Romanowicz-Makowskal $\mathrm{H}$, Strzelczyk J, Janiak A, et al. Comparative evaluation of p53 mutation in pancreatic adenocarcinoma and chronic pancreatitis. Hepatogastroenterology. 2006;53(70):608-12.

Tan XJ, Lang JH, Lou WZ, Shen K, Xu XY. [Prognostic value of microvessel density and angiogenesis-related molecules in epithelial ovarian cancer]. Zhonghua Zhong Liu Za Zhi. 2008 Apr;30(4):274-8.

Tanigawa N, Amaya H, Matsumura M, Shimomatsuya T, Horiuchi T, et al. Extent of tumor vascularization correlates with prognosis and hematogenous metastasis in gastric carcinomas. Cancer Res. 1996 Jun 1;56(11):2671-6.

Thelen A, Scholz A, Benckert C, Schröder M, Weichert W, Wiedenmann B, et al. Microvessel density correlates with lymph node metastases and prognosis in hilar cholangiocarcinoma. J Gastroenterol. 2008;43(12):959-66.

Thomas HV, Key TJ, Allen DS, Moore JW, Dowsett M, Fentiman IS, Wang DY. A prospective study of endogenous serum hormone concentrations and breast cancer risk in premenopausal women on the island of Guernsey. $\mathrm{Br} \mathrm{J}$ Cancer. 1997;75(7):1075-9.

Tian Y, Ding RY, Zhi YH, Guo RX, Wu SD. Analysis of p53 and vascular endothelial growth factor expression in human gallbladder carcinoma for the determination of tumor vascularity. World J Gastroenterol. 2006;12(3):415-9. 
Torrisani J, Bournet B, Cordelier P, Buscail L. Nouvelles cibles moleculaires dans le cancer du pancreas. Bull Cancer. 2008;95(5):503-12.

Tural S, Gercek A, Konya D, Ozgen S, Toplamoglu H, Ozek MM. Microvessel density and vascular endothelial growth factor expression as predictors of childrens' survival from cerebellar medulloblastoma. J Clin Neurosci. 2009 Jun 11. doi:10.1016/j.jocn.2008.10.026.

Turpin E, Bièche I, Bertheau P, Plassa LF, Lerebours F, de Roquancourt A, et al. Increased incidence of ERBB2 overexpression and TP53 mutation in inflammatory breast cancer. Oncogene. 2002;21(49):7593-7.

Ueba T, Nosaka T, Takahashi JA, Shibata F, Florkiewicz RZ, Vogelstein B, Oda $\mathrm{Y}$, Kikuchi $\mathrm{H}$, Hatanaka $\mathrm{M}$. Transcriptional regulation of basic fibroblast growth factor gene by p53 in human glioblastoma and hepatocellular carcinoma cells. Proc Natl Acad Sci U S A. 1994;91(19):9009-13.

Ueda T, Oda T, Kinoshita T, Konishi M, Nakahashi C, Takahashi S, et al. Neovascularization in pancreatic ductal adenocarcinoma: Microvessel count analysis, comparison with non-cancerous regions and other types of carcinomas. Oncol Rep. 2002;9(2):239-45.

Uzzan B, Nicolas P, Cucherat M, Perret GY. Microvessel density as a prognostic factor in women with breast cancer: a systematic review of the literature and meta-analysis. Cancer Res. 2004;64(9):2941-55.

VEGF and câncer Por Judith H. Harmey

Vermeulen PB, Gasparini G, Fox SB, Toi M, Martin L, McCulloch P, Pezzella F, Viale G, Weidner N, Harris AL, Dirix LY. Quantification of angiogenesis in solid human tumours: an international consensus on the methodology and criteria of evaluation. Eur J Cancer. 1996;32A(14):2474-84.

Vogelstein B, Kinzler KW; p53 function and dysfunction. Cell 70: 523-526, 1992.

Wagner M, Redaelli C, Lietz M, Seiler CA, Friess H, Büchler MW. Curative resection is the single most important factor determining outcome in patients with pancreatic adenocarcinoma. Br J Surg. 2004;91(5):586-94.

Wang ZQ, Li JS, Lu GM, Zhang XH, Chen ZQ, Meng K. Correlation of CT enhancement, tumor angiogenesis and pathologic grading of pancreatic carcinoma. World J Gastroenterol. 2003;9(9):2100-4. 
Weidner N, Folkman J, Pozza F, Bevilacqua P, Allred EN, Moore DH, et al. Tumor angiogenesis: a new significant and independent prognostic indicator in early-stage breast carcinoma. J Natl Cancer Inst. 1992;84(24):1875-87.

Wildiers H, Guetens G, De Boeck G, Verbeken E, Landuyt B, Landuyt W, et al. Effect of antivascular endothelial growth factor treatment on the intratumoral uptake of CPT-11. Br J Cancer. 2003;88(12):1979-86.

Winter JM, Cameron JL, Campbell KA, Arnold MA, Chang DC, Coleman J, et al.1423 pancreaticoduodenectomies for pancreatic cancer: A single-institution experience. J Gastrointest Surg. 2006;10(9):1199-210.

Zureikat $\mathrm{AH}$, McKee MD. Targeted therapy for solid tumors: current status. Surg Oncol Clin N Am. 2008;17(2):279-301. 


\section{Apêndice - Tabela Geral de Observações}

\begin{tabular}{|c|c|c|c|c|c|c|c|c|c|c|c|c|c|c|c|c|}
\hline $\begin{array}{l}\text { numero de } \\
\text { ordem }\end{array}$ & RG-HC & Sexo & Idade & Estadiamento & Tamanho(cm) & $\mathrm{T}$ & $\mathrm{N}$ & Perineural & Vascular & Margem & Grau Histológico & p53 Tumor & vasos por $\mathrm{mm}^{2}$ & \begin{tabular}{|c|} 
Data \\
Procedimento
\end{tabular} & $\begin{array}{c}\text { Atualizaçăo } \\
\text { (meses) }\end{array}$ & \begin{tabular}{|c|} 
situaçắo \\
atual
\end{tabular} \\
\hline 1 & $3183889 \mathrm{~F}$ & $M$ & 41 & IB & 3 & 2 & 0 & presente & \begin{tabular}{|l|} 
ausente \\
\end{tabular} & livre & indiferenciado & neg & 42,4 & $25 / 02 / 97$ & 9,87 & \\
\hline 2 & $13609410 \mathrm{~B}$ & M & 41 & $\| \mathrm{B}$ & 2,9 & 3 & 1 & presente & presente & livre & bem diferenciado & pos & 23,9 & $27 / 11 / 03$ & 10,13 & \\
\hline 3 & $7032304 \mathrm{~J}$ & $M$ & 60 & IB & 2,5 & 2 & 0 & presente & \begin{tabular}{|l|} 
ausente \\
\end{tabular} & livre & bem diferenciado & neg & 35,8 & $26 / 07 / 05$ & 34,60 & vivo com \\
\hline 4 & $3273779 A$ & $\mathrm{~F}$ & 66 & IA & 1,6 & 1 & 0 & presente & \begin{tabular}{|l|} 
ausente \\
\end{tabular} & comprometida & bem diferenciado & pos & 51,7 & 19/01/99 & 19,23 & \\
\hline 5 & $13487709 D$ & $\mathrm{~F}$ & 47 & IB & 5 & 2 & 0 & presente & presente & livre & moderado & neg & 49,1 & $13 / 05 / 03$ & 28,60 & \\
\hline 6 & $13537786 \mathrm{~F}$ & $\mathrm{~F}$ & 75 & $\mathrm{IIB}$ & 2 & 3 & 1 & presente & presente & livre & moderado & pos & 42,4 & $16 / 04 / 01$ & 7,20 & \\
\hline 7 & $3339913 \mathrm{D}$ & $\mathrm{F}$ & 57 & $\mathrm{IIB}$ & 2,3 & 3 & 1 & presente & ausente & comprometida & bem diferenciado & pos & 58,3 & $04 / 07 / 00$ & 35,03 & \\
\hline 8 & $3367940 A$ & M & 56 & IIB & 4 & 3 & 1 & presente & presente & livre & moderado & neg & 76,9 & 20/08/01 & 10,80 & \\
\hline 9 & $13736004 \mathrm{G}$ & M & 69 & $11 \mathrm{~B}$ & 6 & 3 & 1 & presente & presente & livre & bem diferenciado & neg & 23,9 & $29 / 05 / 06$ & 17,70 & \\
\hline 10 & $13590643 B$ & $\mathrm{M}$ & 55 & $\mathrm{IIB}$ & 4,5 & 3 & 1 & presente & ausente & comprometida & moderado & neg & 33,2 & $13 / 08 / 03$ & 17,30 & \\
\hline 11 & $13523924 \mathrm{~K}$ & $\mathrm{~F}$ & 54 & $\mathrm{IIB}$ & 2,5 & 3 & 1 & presente & presente & comprometida & moderado & pos & 25,2 & $09 / 01 / 01$ & 23,43 & \\
\hline 12 & $3313626 \mathrm{H}$ & $\mathrm{F}$ & 54 & $\mathrm{IIB}$ & 2,5 & 2 & 1 & presente & presente & comprometida & moderado & neg & 47,7 & 18/10/99 & 18,17 & \\
\hline 13 & $13597904 \mathrm{~J}$ & M & 57 & $\| \mathrm{B}$ & 2 & 3 & 1 & presente & presente & comprometida & moderado & neg & 33,2 & $20 / 10 / 03$ & 16,73 & \\
\hline 14 & $13514376 \mathrm{H}$ & $\mathrm{M}$ & 71 & IB & 2,2 & 2 & 0 & presente & ausente & livre & bem diferenciado & neg & 43,8 & $29 / 08 / 00$ & 0,33 & \\
\hline 15 & $3205070 \mathrm{D}$ & $\mathrm{F}$ & 65 & III & 3,2 & 4 & 0 & presente & presente & livre & bem diferenciado & neg & 34,5 & $05 / 08 / 97$ & 11,90 & \\
\hline 16 & $3125286 \mathrm{D}$ & $\mathrm{M}$ & 40 & $\| \mathrm{B}$ & 3,2 & 3 & 1 & presente & ausente & livre & bem diferenciado & neg & 53,0 & $12 / 02 / 96$ & 35,50 & \\
\hline 17 & 135218111 & $\mathrm{~F}$ & 73 & $\mathrm{IIB}$ & 2 & 3 & 1 & presente & presente & livre & moderado & pos & 33,2 & $20 / 11 / 00$ & 18,37 & \\
\hline 18 & $2660675 J$ & $\mathrm{~F}$ & 59 & IA & 2 & 1 & 0 & presente & presente & livre & moderado & pos & 37,1 & $20 / 02 / 97$ & 8,40 & \\
\hline 19 & 13604796G & $\mathrm{F}$ & 67 & IIA & 2,7 & 3 & 0 & presente & ausente & livre & bem diferenciado & pos & 25,2 & $02 / 12 / 03$ & 54,40 & viva sem \\
\hline 20 & 135943001 & $\mathrm{~F}$ & 51 & $\mathrm{IIB}$ & 2,5 & 2 & 1 & presente & presente & livre & moderado & neg & 33,2 & $02 / 09 / 03$ & 16,33 & \\
\hline 21 & 13726949D & $\mathrm{F}$ & 63 & IIB & 1,8 & 3 & 1 & presente & ausente & livre & moderado & neg & 34,5 & $14 / 03 / 06$ & 3,57 & \\
\hline 22 & $13566771 \mathrm{~A}$ & M & 68 & III & 4 & 4 & 1 & presente & ausente & comprometida & bem diferenciado & neg & 37,1 & $21 / 01 / 02$ & 10,57 & \\
\hline 23 & $13472906 \mathrm{H}$ & $\mathrm{M}$ & 49 & IIB & 3,5 & 3 & 1 & presente & ausente & livre & bem diferenciado & neg & 39,8 & $14 / 01 / 03$ & 1,63 & \\
\hline 24 & $13500381 \mathrm{C}$ & M & 65 & $\| \mathrm{B}$ & 2,8 & 3 & 1 & ausente & ausente & - & bem diferenciado & neg & 21,2 & $26 / 10 / 99$ & 39,37 & \\
\hline 25 & $13656792 D$ & $\mathrm{~F}$ & 65 & $\| \mathrm{A}$ & 4,5 & 3 & 0 & presente & \begin{tabular}{|l|} 
ausente \\
\end{tabular} & livre & bem diferenciado & pos & 45,1 & $22 / 11 / 04$ & 42,83 & viva sem \\
\hline
\end{tabular}




\begin{tabular}{|c|c|c|c|c|c|c|c|c|c|c|c|c|c|c|c|c|}
\hline \begin{tabular}{|l|} 
numero de \\
ordem
\end{tabular} & RG-HC & Sexo & Idade & Estadiamento & Tamanho(cm) & $T$ & $\mathrm{~N}$ & Perineural & Vascular & Margem & Grau Histológico & p53 Tumor & vasos por $\mathrm{mm}^{2}$ & $\begin{array}{c}\text { Data } \\
\text { Procedimento }\end{array}$ & \begin{tabular}{|c|} 
Atualizaçăo \\
(meses)
\end{tabular} & \begin{tabular}{|c|} 
situaçăo \\
atual
\end{tabular} \\
\hline 26 & $2345461 \mathrm{~K}$ & M & 63 & $\| A$ & 2,4 & 3 & 0 & presente & presente & comprometida & moderado & neg & 63,6 & $11 / 11 / 02$ & 11,80 & \\
\hline 27 & $3307094 \mathrm{~J}$ & $M$ & 58 & IB & 4 & 2 & 0 & presente & presente & comprometida & indiferenciado & neg & 38,5 & $06 / 09 / 99$ & 4,73 & \\
\hline 28 & $3367054 \mathrm{H}$ & $M$ & 67 & III & 3,1 & 4 & 1 & presente & presente & comprometida & indiferenciado & neg & 84,9 & $08 / 04 / 02$ & 27,77 & \\
\hline 29 & $3329935 \mathrm{~B}$ & $\mathrm{~F}$ & 77 & $\| \mathrm{A}$ & 3,2 & 3 & 0 & presente & ausente & comprometida & moderado & pos & 90,2 & $21 / 02 / 00$ & 19,33 & \\
\hline 30 & $2894247 C$ & $M$ & 65 & $\| A$ & 4 & 3 & 0 & presente & presente & livre & indiferenciado & pos & 51,7 & $21 / 01 / 93$ & 3,00 & \\
\hline 31 & $13761650 \mathrm{~A}$ & $M$ & 60 & $\| B$ & 2 & 3 & 1 & presente & ausente & comprometida & moderado & neg & 62,3 & $12 / 12 / 06$ & 0,57 & \\
\hline 32 & $1356664 \mathrm{k}$ & M & 50 & $\| B$ & 4 & 3 & 1 & presente & ausente & livre & moderado & pos & 23,9 & $24 / 01 / 02$ & 25,17 & \\
\hline 33 & $13524830 \mathrm{~K}$ & $\mathrm{~F}$ & 68 & $\| \mathrm{B}$ & 6,5 & 3 & 1 & presente & presente & livre & indiferenciado & neg & 53,0 & 08/01/01 & 89,20 & viva sem \\
\hline 34 & $13578911 \mathrm{~F}$ & $\mathrm{~F}$ & 49 & $\| \mathrm{A}$ & 3,5 & 3 & 0 & presente & ausente & livre & bem diferenciado & pos & 29,2 & $15 / 07 / 02$ & 16,90 & \\
\hline 35 & $5290417 \mid$ & $\mathrm{F}$ & 53 & $\| \mathrm{A}$ & 3 & 3 & 0 & presente & presente & livre & moderado & neg & 45,1 & $14 / 02 / 02$ & 34,03 & \\
\hline 36 & $3235344 \mathrm{~A}$ & $\mathrm{~F}$ & 55 & $\| B$ & 5,5 & 3 & 1 & presente & presente & comprometida & bem diferenciado & pos & 63,6 & $30 / 03 / 98$ & 3,70 & \\
\hline 37 & $3235961 \mathrm{G}$ & $\mathrm{F}$ & 49 & IIII & 6 & 4 & 0 & presente & presente & comprometida & moderado & neg & 39,8 & $28 / 04 / 98$ & 0,43 & \\
\hline 38 & $13575323 G$ & $\mathrm{~F}$ & 60 & $\| B$ & 1,5 & 1 & 1 & ausente & presente & livre & bem diferenciado & neg & 21,2 & 06/05/02 & 22,93 & \\
\hline 39 & $13490295 \mathrm{H}$ & $\mathrm{F}$ & 67 & IA & 2 & 1 & 0 & presente & ausente & livre & bem diferenciado & neg & 49,1 & $07 / 05 / 03$ & 33,17 & \\
\hline 40 & $2480237 \mathrm{E}$ & $\mathrm{F}$ & 51 & $\| B$ & 5 & 3 & 1 & presente & presente & comprometida & bem diferenciado & pos & 88,8 & $12 / 07 / 94$ & 11,50 & \\
\hline 41 & $3275915 \mathrm{E}$ & $\mathrm{F}$ & 40 & $\| \mathrm{A}$ & 3,3 & 3 & 0 & ausente & ausente & livre & bem diferenciado & pos & 94,1 & $22 / 02 / 99$ & 42,87 & \\
\hline 42 & $3325354 \mathrm{H}$ & $\mathrm{F}$ & 59 & $\| B$ & 4 & 3 & 1 & presente & ausente & livre & bem diferenciado & neg & 55,7 & $14 / 07 / 00$ & 4,30 & \\
\hline 43 & $3255216 \mathrm{~K}$ & $M$ & 50 & $\| B$ & 3 & 2 & 1 & ausente & presente & comprometida & indiferenciado & pos & 62,3 & $22 / 09 / 98$ & 1,70 & \\
\hline 44 & $2060503 B$ & $\mathrm{~F}$ & 65 & $\| \mathrm{B}$ & 4,5 & 3 & 1 & presente & presente & comprometida & bem diferenciado & pos & 29,2 & $12 / 12 / 01$ & 10,47 & \\
\hline 45 & $13645288 \mathrm{~J}$ & $M$ & 57 & IA & 1,5 & 1 & 0 & presente & ausente & livre & bem diferenciado & pos & 50,4 & $27 / 08 / 04$ & 20,80 & \\
\hline 46 & $2039062 \mathrm{~K}$ & M & 69 & $\| A$ & 5 & 3 & 0 & presente & ausente & livre & bem diferenciado & neg & 37,1 & 04/03/02 & 18,40 & \\
\hline 47 & $13466949 \mathrm{~A}$ & $\mathrm{~F}$ & 43 & $\| B$ & 3,5 & 3 & 1 & presente & presente & comprometida & moderado & pos & 53,0 & $20 / 11 / 02$ & 11,37 & \\
\hline 48 & $13451834 \mathrm{~K}$ & $\mathrm{M}$ & 70 & $\| B$ & 4 & 3 & 1 & presente & ausente & livre & indiferenciado & neg & 54,4 & $06 / 08 / 02$ & 7,00 & \\
\hline 49 & $13666302 \mathrm{H}$ & $\mathrm{F}$ & 46 & $\| B$ & 3 & 3 & 1 & presente & presente & livre & moderado & neg & 43,8 & $10 / 01 / 05$ & 24,23 & \\
\hline
\end{tabular}

